\title{
An Experimental Evaluation of Particle Impact Dampers Applied on the Tool for Milling of Hardened Steel Complex Surface
}

\section{Victor Rossi Saciotto ( $\sim$ v212029@dac.unicamp.br)}

UNICAMP: Universidade Estadual de Campinas https://orcid.org/0000-0002-1237-7708

\section{Anselmo Eduardo Diniz}

University of Campinas

\section{Research Article}

Keywords: Milling, Damper, Impact, Tool Vibration

Posted Date: September 9th, 2021

DOI: https://doi.org/10.21203/rs.3.rs-873629/v1

License: (c) (1) This work is licensed under a Creative Commons Attribution 4.0 International License. Read Full License

Version of Record: A version of this preprint was published at The International Journal of Advanced Manufacturing Technology on January 26th, 2022. See the published version at https://doi.org/10.1007/s00170-022-08782-4. 


\title{
An experimental evaluation of particle impact dampers applied on the tool for milling of hardened steel complex surface
}

\author{
Victor Rossi Saciotto \\ School of Mechanical Engineering, University of Campinas, Campinas, SP, Brazil \\ v212029@dac.unicamp.br \\ https://orcid.org/0000-0002-1237-7708
}

\author{
Anselmo Eduardo Diniz \\ School of Mechanical Engineering, University of Campinas, Campinas, SP, Brazil \\ anselmo@fem.unicamp.br \\ https://orcid.org/0000-0001-6393-0027
}

\begin{abstract}
In the manufacturing of dies and molds, vibrations may represent serious problems, since the finishing tool used is usually slender (high Length / Diameter ratio) in order to machine deep cavities with complex geometry, typical of these products. Vibration is an undesirable phenomenon in any machining operation as it can lead to poor surface finish, lower material removal rate and increased tool wear. The use of impact dampers in the tool has proven to be an effective method for reducing vibration in machining processes. Damping occurs through energy dissipation and linear momentum exchange during intermittent collisions between the main structure (in this case the milling tool) and a free mass (spheres or cylinders placed within a tool cavity). Although efficient, these types of dampers are highly nonlinear. Thus, the aim of this work is to analyze the effect of different materials and geometries (steel spheres, tungsten spheres and steel cylinders) acting as impact dampers inside a ball nose end milling tool. To do so, milling of a convex D6 steel surface was performed, comparing commercial tool holders with dampened ones. The results showed that the tools with impact dampers generated lower values of roughness in the workpiece (around $30 \%$ of the value observed in the conventional steel tool holder for the case of steel cylinders and around $40 \%$ for both spheres) and presented lower levels of vibration when compared to the same tool without the impact damper, mainly in the machining of workpiece regions where radial and tangential forces are predominant. The tool which used tungsten spheres generated roughness surfaces similar to those obtained with steel spheres, while the tool that used steel cylinders only generated lower roughness in the regions where the axial force component is not predominant, which shows that their performance is highly dependent on the resulting force direction.
\end{abstract}

Keywords: Milling; Damper; Impact; Tool Vibration. 


\section{Declarations}

Funding: The research leading to these results received funding from "Conselho Nacional de Desenvolvimento Científico e Tecnológico - CNPq" under Grant Agreement No 131984/2018-7 and “Fundação de Amparo à Pesquisa do Estado de São Paulo - FAPESP” (2013/00551-7).

Conflicts of interest/Competing interests: Not applicable.

Availability of data and material: Not applicable.

Code availability: Not applicable.

Ethics approval: Not applicable.

Consent to participate: Not applicable.

Consent for publication: Not applicable.

Acknowledgements: The authors would like to thank the "Conselho Nacional de Desenvolvimento Científico e Tecnológico - CNPq" for providing the scholarship, "Fundação de Amparo à Pesquisa do Estado de São Paulo - FAPESP” and DEMM-FEM/UNICAMP. 


\section{INTRODUCTION}

With the increasing use of high speed machining techniques, vibrations may represent serious problems, since due to the high speeds involved, the local modes of the spindle-toolholder-tool subsystem are excited, impairing the achievement of tight tolerances and low surface finish of the workpiece and causing tool breakage and damage to the machine structure [1]. When it comes to the milling of molds and dies, in addition to the high speeds involved in the process, another aggravating factor for the occurrence of excessive vibrations is the fact that the tool is quite slender (high L/D - length/diameter ratio), since it needs to copy complex forms, often with small radii and usually in deep cavities. Thus, the diameter of the tool is reduced, and its length increased, factors that contribute to the reduction of its stiffness. In addition, low roughness is normally required for dies and molds, in order to avoid the use of other processes after milling, like electro-erosion and polishing.

During the milling of dies and molds with 3-axis machines, due to the circular shape of the tool, the angle formed between the tool axis and the workpiece surface changes according to the inclination of both [2]. This angle has a strong influence on the components of the machining force. When the tool axis is parallel to the surface of the workpiece, only the tangential and radial force components are present, the axial component is close to zero. As this angle decreases, the radial component value decreases and the axial component value increases. In ball nose end mills, the radial direction of the tool is not very rigid, as only the tool body resists deflection [3]. Thus, one of the main problems in machining using slender tools occurs near vertical walls, where the radial force is greater and the tool deflection and its consequent vibration affect the surface quality and dimensional accuracy of the workpiece [4].

Machining processes may generate three different types of mechanical vibrations, which arise due to the lack of dynamic stiffness of the elements of the system, consisting of the machine, the tool holder, the cutting tool and workpiece. These types of vibrations are known as free vibrations, forced vibrations and self-excited vibrations [5-7].

Free vibrations occur when the system is displaced from its equilibrium with no external forces causing the motion. In machining operations, free vibrations appear, for example, as a result of the collision between the tool and workpiece. [5]

Forced vibrations occur due to external excitations and are all those that occur due to dynamic forces applied to a stable system, for example: cutting forces variation, caused by inhomogeneities in the workpiece material, built-up edge breakage and changes in chip cross-section; interrupted cutting processes, such as milling; internal sources, such as unbalanced rotating elements; and external disturbances, transmitted from the floor to the machine tool [8]. When it comes to forced vibrations, their reduction can be achieved through the use of different machining techniques, tool geometries and optimized cutting parameters, allowing a more stable cut [9], as per example the use of sharper edges, smaller nose radius, larger rake angle for less chip deformation or even the reduction of machining parameters.

Self-excited vibrations originates in the system itself and extract energy to start and grow from the alternated force produced by the interaction between the tool and the workpiece during the machining process. This type of vibration raises the instability of the system and is the most undesirable and least 
controllable one $[6,7]$. For this reason, it has been a topic of great interest for academic and industrial research

The occurrence of vibrations can be minimized through the modeling of the system and subsequent appropriate choice of machining parameters, or through the addition of dampers when seeking greater productivity, thus maintaining a high rate of chip removal [5]. Dampers used in machining operations can be divided into active or passive systems. Active systems have the ability to monitor the dynamic state of the machine tool-part system, diagnose a given occurrence and actively execute decisions that changes, if necessary, the system to a more suitable situation. In this way, the active system measures a vibration parameter and introduces a controlled force signal, in response to the measured signal, through an actuator. That is, an external energy is introduced and applied to the vibrating structure [10]. An active system is implemented using actuators, controllers and sensors to control the vibration in the machining process [11], [12].

Passive dampers, despite not being able to modify their operation according to a system response, are preferred, as they are simpler and cheaper to build, do not need an energy source for their operation and normally do not suffer degradation, even in harsh environments [8]. The principle of passive damping is to convert mechanical energy into another forms, for example, heat. For that, it includes strategies based on the modification of certain elements of the structure, in order to modify the behavior of the system [8].

An example of passive damper used in machining is the TMD (Tuned-Mass Damper), whose working principle is an inertial mass added to a structure. The added mass experiences part of the vibration acting on the main structure and generates the damping [13]. A TMD used in machining, which is commercially available, is the Silent Tools ${ }^{\mathrm{TM}}$ line, from Sandvik Coromant. In this system, inside the tool holder there is a preset passive dampening mechanism, in which a mass in contact with a rubber act as a damper. These tools were developed to meet the need for higher material removal rates combined with reduced vibration [14]. Despite the efficiency in reducing vibrations, this type of tool has a very high cost when compared to simpler systems. Furthermore, the TMD performs satisfactorily in a limited frequency range [15], which makes each tool holder suitable for a particular operation and for specific machining parameters.

Another type of passive damper is the impact damper, which are one of the most effective passive control methods for suppressing/minimizing vibrations. The advantages of this type of damper are that they are cheap, simple to manufacture and provide good performance under a wide range of accelerations and frequencies [16]. They are composed of either one or multiple masses placed inside a cavity connected to a vibrating structure. In this way, the energy is dissipated through the impact and friction of the added masses with the structure to be damped. [17]. They are highly non-linear since the damping is derived from a combination of energy loss through friction and partially inelastic collisions with the structure and the particles themselves. There is also a linear momentum exchange mechanism, in which the momentum is transferred from the structure to the particles. This energy is then stored in the particles in terms of kinetic energy and deformation $[10,11]$.

In order to understand the highly nonlinear behavior of the impact dampers, Albuquerque [18] modeled and experimented an impact damper. Forced vibrations were performed and it was found that a specific gap value between the particle and the structure provides an optimum damping efficiency. The 
vibration attenuation depends, first, on the collision between the particles and the structure moving against each other. The greatest attenuation is obtained when, at the instant of contact, the impact mass and the structure have opposite velocity direction. In very small gaps, there is a reduction in the efficiency of the impact damper, since part of the impacts occurs when the velocities are in the same direction. When the gap is too large, there will be no collision between particles and structure. Thus, the gap must be adequately designed for greater efficiency, since a too small or too large gap causes unsatisfactory or even no damping [18].

It should be noted, however, that a gap is only considered small or large when it is related to the system vibration amplitude. When the oscillation of the system has its amplitude reduced, the optimum clearance becomes smaller, since the displacement of the structure related to gap dimension becomes smaller. Therefore, according to the system vibration amplitude and frequency, there is a distinct ideal gap [18]. Probably, the greatest complexity in impact dampers design occurs in the understanding of how each parameter influences the system dynamics.

Sims et al. [19] experimented a particle impact damper during a milling operation, in which the element of greatest instability was the workpiece. In this way, the damper was attached to the body of the workpiece. With the use of the dampers, the maximum depth of cut was increased from $0.2 \mathrm{~mm}$ to $7 \mathrm{~mm}$, maintaining the surface roughness. Also, according to the same authors, when compared to other damping techniques, such as TMDs (Tuned Mass Dampers), the impact damper is effective for a wider frequency range, with a smaller size and lower damper mass.

One of the first works to use the impact damping system inside cutting tools was that of Suyama et al. [20], who performed tests for the internal turning of hardened steel SAE 4340 with tool holders of steel, carbide and steel with several small steel spheres acting as particle dampers. The use of particle dampers increased the maximum tool overhang from $68 \mathrm{~mm}$ to $80 \mathrm{~mm}$ in comparison to the conventional steel tool holder, maintaining the cut stable.

Diniz et al. [21] evaluated the use of impact dampers in the internal turning of hardened steel SAE 4340. For this purpose, they drilled an $8.32 \mathrm{~mm}$ diameter hole in the axial direction of the tool holder. Steel spheres with diameters slightly smaller than the hole $(5,6.5$, and $8 \mathrm{~mm})$ were inserted in the cavity. The tool with $8 \mathrm{~mm}$ spheres showed the best results and allowed the increasing of the maximum overhang of the conventional tool from $70 \mathrm{~mm}(\mathrm{~L} / \mathrm{D}=4.375)$ to $128 \mathrm{~mm}(\mathrm{~L} / \mathrm{D}=8)$, maintaining the same roughness values and without chatter occurrence. Based on these results, it was inferred that the damping caused by the impact of the spheres is greater when they have greater mass, associated with a smaller gap between spheres and cavity, since the damping effect depends on the exchange of linear momentum between the spheres and the tool, which is related to the sphere mass, impact velocity and number of collisions. The increasing in mass and the gap decreasing, which possibly increases the effectivity of collisions, contributed to a greater damping effect. [21]

Galarza et al. [22] evaluated the impact damper effectiveness during a ball nose end milling of a convex D6 steel surface with $60 \mathrm{HRc}$ hardness. In order to apply the damping system, they drilled a $6 \mathrm{~mm}$ diameter and $130 \mathrm{~mm}$ length hole in the tool axial direction. Then, the hole was filled with spheres of 5.9, 5.5 and $5 \mathrm{~mm}$ diameter. The results showed that the lowest surface roughness values was obtained for the 
tool with the largest sphere $(5.9 \mathrm{~mm})$. Therefore, it was again proved that the best results were obtained for smaller gaps and higher sphere mass.

However, the application of impact dampers in rotating tools has not been widely studied. The aim of this work is to reduce the tool vibration level during the milling of dies and molds through the application of an impact damper constructed with the addition of either steel or tungsten spheres or steel cylinders in the axis of the tool holder, in order to determine the best damping element material and geometry to reduce the vibration level of a slender milling tool. For this, the average roughness of the workpiece at the beginning and end of tool life, tool life and the force variation during machining will be analyzed.

\section{MATERIALS AND METHODS}

For the milling tests, all the experiments were done in a Mori Seiki SV40 three-axis vertical machining center with $22 \mathrm{~kW}$, maximum speed of 12,000 rpm and GE Fanuc MSC-518 computer numerical control. In order to obtain forces in $\mathrm{X}, \mathrm{Y}$ and $\mathrm{Z}$ directions during machining, a KISTLER 9295B piezoelectric dynamometer was used, connected to a KISTLER 5019B signal conditioner fixed on the machine worktable, which transmits the force signals through an A/D National Instruments PCI-6025E acquisition plate, for a computer with LabVIEW 2011 software. A low pass filter was used in the conditioner with a cutoff frequency of $5 \mathrm{kHz}$, an acquisition rate of $10 \mathrm{kHz}$ and a conversion rate of 400 N/V. Subsequently, a digital bandpass filter between 150 and 2,000 Hz was applied, eliminating network noise in the $60 \mathrm{~Hz}$ frequency and its first harmonic. The frequency was limited to $2,000 \mathrm{~Hz}$, since the highest frequencies found in the signal were in the order of 1,500 Hz. The fixation of the dynamometer and the workpiece is shown in Fig. 1.

Fig. 1 Workpiece and dynamometer fixation.

To measure the tool flank wear, a Quimis Q714ZT2 optical microscope was used, connected to a 1.3 megapixel Motic digital camera, with a maximum zoom of 80 times. Image acquisition and processing were performed using the Motic Image Plus software. The wear was measured each time the tool had cut a full machining area of the workpiece (one quarter of the circle with $40 \mathrm{~mm}$ thickness - see Fig. 5). This procedure was repeated until the tool maximum flank wear $\left(\mathrm{V}_{\mathrm{Bmax}}\right)$ reached $0.2 \mathrm{~mm}$. This value was used based on the work of [21] and [22], since in finishing operations, flank wear may not reach high values, otherwise it could harm the workpiece surface finish. To obtain the mean roughness (Ra) a portable Mitutoyo Surftest SJ-210 roughness tester was used, with a cut-off $(\lambda \mathrm{c})$ of $0.8 \mathrm{~mm}$ [23], connected to a computer containing the SurfTest ${ }^{\circledR}$ SJ210 software. The roughness measurement was executed in the direction perpendicular to the tool feed.

An AISI D6 steel specimen, quenched and tempered presenting hardness of 60HRc was used as the workpiece, which dimensions may be observed in Fig. 2.

Fig. 2 Schematic drawing of the workpiece. 
Commercial steel tool holders R216F-12A16S-085, one original and another with a $6.1 \mathrm{~mm}$ diameter axial hole were used, as well as a R216F-12A16C-085 carbide tool holder, all from Sandvik Coromant. The carbide tool holder tends to have much lower vibration levels, since it has an elastic modulus about three times greater than that of steel, which contributes to the reduction of vibration amplitudes. For all the cases studied, inserts with a circular edge of 12 mm diameter R216F-12 30 E-L 1010 made of ISO H10 carbide with PVD coating of TiAlN, also from Sandvik Coromant, were used.

The impact dampers were inserted into the tool holder as shown in Fig. 3. First, a $6 \mathrm{~mm}$ diameter hole was drilled in the axial direction of the tool along its central axis. Subsequently, a reamer was used in order to obtain a final hole diameter of $6.1 \mathrm{~mm}$. Both, the spheres and the cylinders have a diameter equal to $6 \mathrm{~mm}$. Thus, a maximum diametrical clearance of $0.1 \mathrm{~mm}$ is maintained. To adjust the axial clearance between the spheres, an M8x1.5 thread with $15 \mathrm{~mm}$ length was made, adjusted with an internal hexagonal screw, thus the clearance in the axial direction remained constant for all tested configurations. The tool overhang used (distance between the tool fixation and the tool tip) was $85 \mathrm{~mm}$ (Fig. 3). The choice of diameter for spheres and cylinders was based on the Galarza et al. [22] work. These authors carried out a study with the same steel tool holder, with steel spheres of different diameters acting as dampers, concluding that the greatest damping was observed for smaller gaps $(0.1 \mathrm{~mm})$ between the structure and the spheres, that is, spheres with larger diameters. Thus, maintaining a maximum gap of $0,1 \mathrm{~mm}$, tests were performed varying the material and geometry of the damper.

Fig. 3 Schematic drawing of the tool holder with cylinders (a) and spheres (b).

As the impact damping principle uses the linear moment exchange that occurs during intermittent collisions, it was decided, in addition to steel spheres, to use a material with higher density in order to increase the damper mass and thus obtain greater attenuation of vibration during each impact. The commercially viable material with the highest density found was tungsten, which has a density of 14.95 $\mathrm{g} / \mathrm{cm} 3$, about 1.9 times greater than steel density. Still aiming to increase the damper mass, but this time without changing the damper material, it was also decided to use steel cylinders. Therefore, to carry out the tests, five different tool configurations were used, as shown in Table 1

Table 1 Configurations for each test.

\begin{tabular}{ccc}
\hline $\mathbf{n}^{\circ}$ & Tool holder type & Damper \\
\hline 1 & Solid Steel & No damper \\
2 & Solid Carbide & No damper \\
3 & Steel with $\varnothing 6,1 \mathrm{~mm}$ hole & Steel spheres $\varnothing 6 \mathrm{~mm}$ \\
4 & Steel with $\varnothing 6,1 \mathrm{~mm}$ hole & Tungsten spheres $\varnothing 6 \mathrm{~mm}$ \\
5 & Steel with $\varnothing 6,1 \mathrm{~mm}$ hole & Steel cylinders $\varnothing 6 \mathrm{~mm}$ \\
\hline
\end{tabular}

The area of the workpiece machined during the tests corresponds to a circular surface with a radius of $30 \mathrm{~mm}$ (Fig. 2), on which milling was performed with 3 programmable axes, that is, always keeping the tool in the vertical direction. Thus, when the tool is cutting region 3 (Fig. 4), the radial force components 
will be quite significant. This is the most critical region during the operation, with the tendency to increase vibrations, since the radial direction of the tool is not very rigid, as only the tool body, which has a high $\mathrm{L} / \mathrm{D}$ ratio, resists deflection.

During the tests, milling was performed in a concordant descending path, from regions 1 to 3 (Fig. 4 and Fig. 5a), since the tests carried out by Kull Neto et al. [24] and Galarza et al. [22] showed that, during copy milling, this strategy generates a better surface finish. All the measurements were performed considering a lead angle of $5^{\circ}$ for region $1,45^{\circ}$ for region 2 and $85^{\circ}$ for region 3 , as illustrated by the blue areas highlighted in Fig. 4.

Fig. 4 Tool feed path during machining.

The machining parameters used to carry out the experiments are shown in Table 2.

Table 2 Machining parameters used.

\begin{tabular}{cccc}
\hline $\begin{array}{c}\text { Spindle Speed } \\
(\mathbf{R P M})\end{array}$ & $\mathbf{f}_{\mathbf{z}}(\mathbf{m m})$ & $\mathbf{a}_{\mathbf{p}}(\mathbf{m m})$ & $\mathbf{a}_{\mathbf{e}}(\mathbf{m m})$ \\
\hline 11000 & 0,1 & & \\
\hline
\end{tabular}

Firstly, tests were carried out with the carbide and steel commercial tool holders, without dampers addition, until the tool reached a maximum tool flank wear $\mathrm{V}_{\mathrm{Bmax} \text {. }}$ of $0.2 \mathrm{~mm}$ (tool life tests). The tool wear were always measured in the region with the largest diameter of the insert, since it is the region that experiences the highest cutting speeds. Force levels in $\mathrm{X}, \mathrm{Y}$ and $\mathrm{Z}$ directions were acquired 5 times during each pass (the pass corresponds to the machined surface across the entire width of the workpiece, see Fig. 5b). In each acquisition, 5 tool cycles were measured (each cycle corresponds to an entry and an exit of the tool in the workpiece, see Fig. 5a), totalizing 25 measured cycles per pass. The average roughness of the workpiece was measured 4 times in the direction of the width of cut (perpendicularly to the feed direction) in each of the 3 regions, also in all passes. In region 1 the roughness was always measured for a $5^{\circ}$ lead angle, in region 2 for a $45^{\circ}$ lead angle and in region 3 for a $85^{\circ}$ lead angle.

Fig. 5 Representation of one cycle and one pass.

Three replicas of the experiment were made with the carbide tool holder and two with the steel tool holder, analyzing tool wear, roughness and force signal. Subsequently, using two inserts with $0.2 \mathrm{~mm}$ of flank wear, 2 replicas were performed to measure the average roughness and forces, this time for the steel tool holder with steel spheres, tungsten spheres and steel cylinders. In order not to encourage wear greater than $0.2 \mathrm{~mm}$, in each of these tests, only $1 / 3$ of the part width was machined, and after each pass it was checked if the wear remained constant.

Then, a new tool life test was carried out with tungsten spheres, this time using a new insert as in the first two tests (tests with conventional tools), analyzing all passes in order to obtain the wear results by chip volume, forces and roughness in all passes. In this case, 2 replicas were also made. The tool life test 
was just performed for the commercial tool holders and the steel tool holder with tungsten spheres, as it was the situation in which better results were expected according to previous simulations with impact dampers [25]. Therefore, it was decided to analyze the life of both conventional tools (solid carbide and steel) compared to the tool with tungsten spheres. In Table 3, all tested configurations are summarized.

Table 3 Tests performed.

\begin{tabular}{|c|c|c|c|c|c|}
\hline \multirow[b]{2}{*}{ Tool holder } & \multirow[b]{2}{*}{ Tool Life } & \multicolumn{2}{|c|}{ Roughness Measurement } & \multicolumn{2}{|c|}{ Force Measurement } \\
\hline & & All passes & $\begin{array}{c}\text { Only with } \\
\mathrm{V}_{\text {B }} \text { máx. }=0,2 \mathrm{~mm}\end{array}$ & All passes & $\begin{array}{c}\text { Only with } \\
\mathrm{V}_{\mathrm{B}} \text { máx. }=0,2 \mathrm{~mm}\end{array}$ \\
\hline Steel & $\checkmark$ & $\checkmark$ & N/A & $\checkmark$ & N/A \\
\hline Carbide & $\checkmark$ & $\checkmark$ & N/A & $\checkmark$ & N/A \\
\hline Steel with steel spheres & $\mathrm{X}$ & $\mathrm{X}$ & $\checkmark$ & $\mathrm{X}$ & $\checkmark$ \\
\hline Steel with tungsten spheres & $\checkmark$ & $\checkmark$ & N/A & $\checkmark$ & N/A \\
\hline Steel with steel cylinders & $\mathrm{X}$ & $\mathrm{X}$ & $\checkmark$ & $\mathrm{X}$ & $\checkmark$ \\
\hline
\end{tabular}

Legend: $\quad \checkmark-$ Yes

$\mathrm{X}-\mathrm{No}$

N/A - Do not apply

\section{RESULTS AND DISCUSSION}

Fig. 6 shows the roughness measurements at the end of tool life, that is, when the tool flank wear was $0.2 \mathrm{~mm}$. Roughness measurements were performed in regions 1,2 and 3 of the workpiece, with four measurements for each region in each of the replicas performed.

Fig. 6 Roughness generated at the end of tool life $\left(V_{B \max }=0.2 \mathrm{~mm}\right)$ in the 3 regions studied.

It could be noted that in region 1, where forces are predominantly oriented in the axial direction of the tool, there is no significant variation in roughness between the tested tools. This happens because the axial direction of the tool is quite rigid no matter the tool holder material, since the tool clamp and the machine head are the responsible elements to resist the compression caused by the axial force. Therefore, the particles (spheres or cylinders) did not experience the required vibration levels in the radial and tangential directions to perform considerable damping, what was also reported by Galarza et al. [22].

In region 3, where the forces in the radial and tangential directions of the tool are more distinguished, there is a significantly greater roughness generated by the conventional steel tool holder, which is expected, since the forces act towards the direction of lowest rigidity of the tool. The use of impact dampers in this case had great efficiency, since in this region the force is oriented towards the impact between the sphere/cylinder and the tool holder wall. The average roughness values were reduced to around $30 \%$ of the value observed in the conventional steel tool holder for the case of steel cylinders and around $40 \%$ for both spheres. In this case, the gap between the particles and the tool holder was enough for the damping to occur in an ideal condition, corroborating the theory proposed by Albuquerque [18]. 
Tool holders with steel and tungsten spheres generated similar levels of roughness, which indicates that for the conditions tested in region 3, there was no significant difference between the use of steel and tungsten spheres. On the other hand, the use of steel cylinders generated slightly smaller roughness. This shows that the $90 \%$ increase in mass caused by the use of tungsten balls did not contribute to the reduction of tool vibration. On the other hand, the $50 \%$ increase in mass associated with geometry modification, caused by the use of the cylinder, showed better results, which indicates that there is an optimal mass ratio between the structure and the damper, in addition to a geometric influence, since for the cylinder dampers the impact of the element against the hole wall occurs in a line and not in a single point, as in the case of spheres.

In region 2, where axial and radial force components are significant, the steel cylinders did not show a good result, maintaining the roughness levels far above the steel and tungsten sphere configurations. With respect to steel and tungsten spheres, the performance in region 2 was also similar between the two configurations.

The carbide tool holder, even without the use of dampers, due to its rigidity about 3 times greater than that of the steel tool holder, provided roughness values much lower than the other configurations in regions 2 and 3, which indicates that the magnitude and the variation of forces were not enough to cause excessive vibrations of the tool.

Fig. 7 shows the average roughness levels in the first pass of the tool, that is, with a fresh tool. Roughness tests with fresh tools were carried out for the commercial tool holders made of steel and carbide and for the tool holder with tungsten spheres.

Fig. 7 Roughness generated during the first pass of the tool in the 3 regions studied.

The roughness levels for the steel holder are much lower at the beginning of tool life than at the end of life (compare Fig. 6 with Fig. 7), with averages for Ra between $0.6 \mu \mathrm{m}$ and $0.7 \mu \mathrm{m}$ (Fig. 7). This shows that wear directly contributed to the increase in roughness, which was due to the increase in force levels as $\mathrm{V}_{\mathrm{Bmax}}$ increased. The tool with tungsten spheres generated slightly higher levels of roughness when compared to the conventional steel tool holder, but it still maintains the roughness at levels considered low, with an average of Ra lower than $0.8 \mu \mathrm{m}$. In this case (fresh tool), as the acting forces are smaller, the effect of the impact damper was not observed as it was for worn tools (Fig. 6). Therefore, when the insert wear is not significant, the use of tungsten spheres did not bring benefits to the surface finish of the workpiece.

The carbide tool holder, in all 3 regions, generated the lowest roughness levels in the workpiece (less than $0.4 \mu \mathrm{m}$ ), which again can be explained by its static stiffness, about 3 times greater than that of the steel tool holder. In this case, even when the force levels are lower, it is noted that the carbide tool holder is better than the other two tool configurations.

Fig. 8 shows the tool maximum flank wear along all passes. The straight lines with the same colors correspond to the replicas tested. Tool wear was observed using an optical microscope to measure flank wear and observe any possible tool damage.

Fig. 8 Tool flank wear by chip volume produced in $\mathrm{mm}^{3}$ 
Note that the wear rate varies significantly after the first pass, ranging from $0.060 \mathrm{~mm}$ to $0.140 \mathrm{~mm}$. For the carbide tool, the highest initial wear value was obtained in two tests, even generating a low level of roughness. Therefore, the high variation of wear in the first pass may be due to an inherent position error of the insert fixation on the tool holder. From the second pass onwards, the wear rate is similar for all tools, except for one of the tests in the carbide tool holder, which showed a higher wear rate. Therefore, it was decided to carry out another replica for this configuration. For a better understanding of the data, Fig. 9 shows the tool life in terms of the volume of chip removed, considering a $V_{B \max }=0.2 \mathrm{~mm}$.

Fig. 9 Tool life by chip volume produced in $\mathrm{mm}^{3}$

By analyzing the graph, considering the dispersions, it is concluded that the tool life was not influenced by the tool holder material (steel or carbide) or by the addition of tungsten spheres. Thus, the use of impact dampers and the use of the carbide tool provided lower levels of roughness, but not longer tool lives, which indicates that the vibration experienced by the tool with the steel tool holder was not enough to compromise the tool life even in the worst case scenario.

Fig. 10 shows the force signals in $\mathrm{X}, \mathrm{Y}$ and $\mathrm{Z}$ directions obtained by the dynamometer during the first pass with carbide, steel and steel with tungsten spheres tool holders. Note that, at the beginning of the cut, in region 1 , the axial force ( $\mathrm{Z}$ axis) is predominant, reaching more than $150 \mathrm{~N}$ for steel tools and 200 $\mathrm{N}$ for carbide tools. The large efforts in $\mathrm{Z}$ in region 1 are mainly due to the small effective contact diameter of the tool, which generates a lot of plastic deformation of the material being cut and friction in the contact region [26]. As the tool moves to region 2, there is a significant decrease in the $\mathrm{Z}$ forces; at the end of the cut, in region 3 , the amplitude of forces in $\mathrm{X}$ tends to increase, acting more significantly for the carbide tool, surpassing the values obtained for the force in Z. Region 3 is considered the most critical for the occurrence of vibrations, since it is the region where the efforts in $\mathrm{X}$ and $\mathrm{Y}$, which are oriented in the direction of less rigidity of the tool, tend to be greater.

Fig. 10 Force signals in $\mathrm{X}, \mathrm{Y}$ and $\mathrm{Z}$ directions during the first pass of the tool.

As already shown, the roughness levels at the beginning of the tool life were much lower than those obtained at the end of life, with little difference between the tool with and without impact dampers, which shows that the addition of tungsten spheres did not work in this case. This can be explained mainly due to the low force values obtained. As wear increased, forces, particularly at X, also increased. From that moment on, the impact damper started to have the desired effect, since the wear promoted higher vibration amplitude of the tool holder, which approximated the gap to the ideal condition, improving the damping performance by a higher exchange of linear momentum between the particles and the tool holder.

Fig. 11 shows the force signal in $\mathrm{X}, \mathrm{Y}$ and $\mathrm{Z}$ directions at the end of tool life, that is, with a maximum flank wear of $0.2 \mathrm{~mm}$. A significant increase in efforts in $\mathrm{X}$ and $\mathrm{Z}$ can be seen for steel and carbide tool holders in region 3 , which shows that tool wear contributed significantly to the force increasing. The addition of dampers contributed to a reduction of efforts in region 3. While for the conventional steel tool 
holder the force in $\mathrm{X}$ was around $50 \mathrm{~N}$, the tool with steel cylinders generated $37 \mathrm{~N}$ in the same direction and the tools with steel and tungsten spheres about $20 \mathrm{~N}$. This shows that part of the cutting energy that is applied to the process by the force on the tool is absorbed by the damping particles. To better understand the effects caused by force on the roughness of the workpiece, it is necessary to observe how the effort variation occurred during cutting.

Fig. 11 Force signals in $\mathrm{X}, \mathrm{Y}$ and $\mathrm{Z}$ directions during the first pass of the tool at the end of tool life.

Fig. 12 shows for 2 tool cycles, how the cutting force varies in the $\mathrm{X}$ axis, which is the most significant for the occurrence of vibrations on the tool, since the force in the $\mathrm{Z}$ axis occurs in the most rigid direction of the tool and the $\mathrm{Y}$ axis force is reduced, since the width of cut value, and consequently the contact angle, are reduced.

Fig. 12 Force signal in $\mathrm{X}$ direction for two tool cycles.

Analyzing Fig. 12, a more accentuated instability can be seen in the highlighted regions in the cases of solid steel tool holder and the tool holder with steel cylinders. For a better understanding of the phenomena that occurs in the regions of interest, the analyzed region should be further expanded. To do so, firstly the force signal for the carbide tool holder, which has reached the lowest levels of roughness, was analyzed. The regions of interest were 2 and 3, where a greater tendency for excessive vibrations occurs.

For better visualization of the force signals, the representation is done in the form of a polar diagram, with $\mathrm{X}, \mathrm{Y}$ and $\mathrm{Z}$ axes represented. Fig. 13 shows the peak values of the force signal in ten revolutions for the carbide tool holder, the radius of the circle represents the force value in Newtons.

Fig. 13 Peaks of force signal for the carbide tool holder.

As the tool has 2 cutting edges, there are 20 points for every 10 revolutions of the tool. It is observed that, even for the carbide tool, in which the average roughness levels were always in the order of $0.4 \mu \mathrm{m}$, there is a significant difference in forces between one edge and another, with this difference being practically constant, which indicates that one edge cuts a larger portion of material than the other one. One hypothesis for this occurrence is that, when fixing the insert in the tool holder there is a positioning error, inherent to the process, since the fixation is done by a screw, which causes one of the edges to be placed little more external in relation to the other. The roughness of the workpiece will result from the action of the edge that removes more material, since only this edge removes the deepest layer of material. Thus, in order to understand the force variation that occurs in the tool, it is decided to analyze the peak of forces during 10 revolutions only for the edge that removes the greatest amount of material (Fig. 14).

Fig. 14 Peaks of force signal in one edge for the carbide tool holder. 
In this case, a behavior much closer to the ideal (polar diagram with a circular shape) is observed, which occurs when there is no variation in efforts. Less variation in force levels indicates that the tool in each revolution removes the same portion of material from the workpiece and experiences less vibration. The carbide tool holder experiences small levels of vibration, corroborating the average roughness results. This shows that is not the force magnitude that increase roughness, but its variation, that is, vibration.

Fig. 15 represents the force variation that occurs in the tool for all strategies tested during the machining of region 2 .

Fig. 15 Peaks of force signal in one edge - Region 2

The use of the solid steel tool holder and the tool holder with steel cylinders showed the greatest deviation, which shows that these configurations experienced higher levels of vibration during the machining of region 2, which confirms the higher average roughness values and shows that the damping effect was not satisfactory for the steel cylinders during the cutting in region 2.

As for tools with steel and tungsten spheres, there is a significant improvement in relation to the conventional steel tool (figure closer to a circle), which shows that there was a beneficial effect caused by the impact damping. Even so, the carbide tool holder had a more regular response, both for $\mathrm{X}$ and $\mathrm{Z}$ forces, which shows that its rigidity, about 3 times greater than that of steel, contributed to avoid excessive vibrations.

Fig. 16 represents the force variation that occurs in the tool for all strategies tested during the machining of region 3. The $\mathrm{Y}$ forces, in this case, were not represented in the diagram for steel tool holders, as they have very low values, which can be confounded with signal noise.

Fig. 16 Peaks of force signal in one edge - Region 3

Once again, the carbide tool is the closest to the ideal trajectory. The solid steel tool holder presented the greatest variation of efforts, that is, higher levels of vibration, which justifies the high values of average roughness obtained with this configuration in region 3.

Among the impact damper configurations, steel and tungsten spheres showed similar performance, improved the initial condition (solid steel tool holder), but still did not achieve the performance of the carbide tool holder. Note that the magnitude of forces is much smaller for the tool with spheres when compared to the conventional steel tool holder. Thus, the variation of forces observed in Fig. 16 is much smaller for tools with dampers.

For the tested conditions, the tungsten spheres presented similar results both for workpiece roughness and for tool vibration levels when compared to the steel spheres. This shows that the increase in mass with the use of tungsten (1.9x greater than steel) did not significantly contribute to improve the system's damping. One hypothesis for this to occur is that the increase in the sphere mass makes the impact velocity between the tool body and the sphere smaller, since the exchange of movement amount between the bodies is directly proportional to its mass and velocity. Furthermore, the restitution coefficients of tungsten and steel are different, which makes the speed and number of impacts different as well. 
The tool with steel cylinders, on the other hand, had the best performance among the dampers in region 3, mainly considering the variation of efforts in the $\mathrm{X}$ direction which, as already mentioned, is the direction in which the vibration occurs, contrary to what occurred in region 2 . This indicates that the orientation of forces has a great influence when using cylinders as impact dampers. This result explains the roughness behavior, which had a high value in region 2 when using a damper with steel cylinders, but a much lower value when this same tool cut region 3 (see Fig. 6).

One hypothesis that may explain why this configuration has not been effective in region 2 is the way in which the impact between the cylinder and the tool cavity occurs. The ideal contact occurs when the cylinder wall collides with the cavity, forming a contact line. As in region 2 there is a composition of efforts, mainly in the axial direction, as shown in Fig. 17, the cylinders tend to suffer a greater inclination, impairing the contact with the cavity wall. In other words, the contact did not occur between the cylinder body (damping element) and the cavity wall, but between its edge and the wall. In addition, the axial direction efforts affected the radial movement of the cylinder, since there was friction between the contact surface among the cylinders (friction between a cylinder and the cylinders below and above it), causing a reduction in the efficiency of the impact damper.

Fig. 17 Representation of $\mathrm{X}$ and $\mathrm{Z}$ forces and resulting in region 2: tool with cylinders

In region 3, as shown in Fig. 18, the axial forces were still significant, but with a reduction of more than $50 \%$ of their magnitude, which made the contacts to occur in less unfavorable conditions for the cylinders. Comparing the composition of the forces on the tool in regions 2 and 3 (Fig. 17 and 18) it is seen that the Fxz component was much more inclined towards $\mathrm{X}$ in region 3 (51.21 ${ }^{\circ}$ of inclination against $12.99^{\circ}$ in region 2) and with much smaller magnitude (21.60 $\mathrm{N}$ in region 3 and $96.04 \mathrm{~N}$ in region 2). Therefore, for cylinders to be effective in the damping task, the forces must be predominantly in the plane perpendicular to the tool axis, so that the cylinder-wall collisions actually occur in a line (or close to it). When spheres were used as damping elements, this did not occur, as the sphere-wall collision will always occur at one point.

Fig. 18 Representation of $\mathrm{X}$ and $\mathrm{Z}$ forces and resulting in region 3: tool with cylinders

The use of cylinders as damping particles proved to be more effective when the axial force/radial force ratio is not excessive. However, for dies and molds surfaces with complex trajectories and high axial force ratio, the use of cylinders is not recommended. Steel and tungsten spheres, despite having shown higher roughness in region 3 when compared to cylinders, are recommended, as they maintain more constant roughness levels throughout the workpiece, reaching maximum roughness always lower than 1.2 $\mu \mathrm{m}$, which represents a significant improvement in relation to the steel conventional tool holder, especially in region 3, where the conventional tool reached an average roughness greater than $2 \mu \mathrm{m}$. Among the steel tool holders, it is recommended to use steel spheres, which guarantee similar performance when compared to tungsten ones and have a much lower cost. 
The use of impact dampers in regions 2 and 3 proved to be effective (except for the use of cylinders in region 2) in reducing vibration and roughness levels when compared with the commercial steel tool holder. This happened because in these regions the vibration acting on the tool was sufficient to generate an adequate momentum exchange between the particles (spheres or cylinders) and the tool holder. In region 1 , this did not happen, because the particles did not experience the required vibration levels to perform considerable damping. This corroborates the theory proposed by Albuquerque [18], that according to the system vibration amplitude and frequency, there is a distinct ideal gap between dampers and hole wall. In regions 2 and 3 the gap was ideal for the damping to occur. In region 1 the gap was too large to cause any momentum exchange between the tool holder and the particles. This phenomenon was also observed in Diniz et al. [21] and Galarza et al. [22] work. In their case, the use of larger spheres provided a higher damping to the system, which occurred due to the gap reduction that allowed a higher frequency of impacts between the tool holder and the particles. This fact, associated with a larger mass, contribute to a greater momentum exchange between the spheres and the tool holder and, consequently, higher damping. Moreover, in region 1 , the main movement of the spheres was in the vertical direction ( $Z$ direction) due to the high value of the Fz component in this region. These movements did not stimulate the impacts between spheres and wall and, consequently, did not stimulate the damping phenomenon.

Despite the improvement in tool performance with the use of impact dampers, the carbide tool holders still present the best results, with an average roughness of less than $0.6 \mu \mathrm{m}$ for all regions, since its greater rigidity contributed to a much smaller displacement level of the tool when compared to conventional steel tool holders. However, this type of tool has a much higher cost. Thus, in some cases, there is a greater benefit/cost ratio with the use of impact dampers.

\section{CONCLUSIONS}

The results of this work on the development of a slender milling tool with impact dampers allow us to conclude, for hardened steel milling in conditions similar to those experienced in this work that:

- The use of impact dampers contributed to the reduction of the average roughness and vibration amplitudes in relation to the solid steel tool holder, with similar performance between steel and tungsten spheres. Thus, the use of steel spheres, which is cheaper, should be preferred.

- The use of steel cylinders acting as impact dampers is not recommended for situations where the axial force is considerable, which shows that their performance is highly dependent on the resulting force direction.

- The carbide tool holder presented the best performance in terms of reducing vibrations and obtaining lower levels of average roughness when compared to all tested steel tools. Therefore, even with the damping generated by the impact dampers, the fact that the carbide tool holder has a rigidity about 3 times greater, made its results better. However, this type of tool has a higher cost when compared to the steel tool.

- The vibration experienced by the tool, even in the worst case, did not influence the tool life or its wear rate. 
Future studies are required to determine if tungsten spheres are more effective when compared to steel spheres in situations where the tool has greater amplitudes of vibration.

\section{REFERENCES}

[1] Quintana G, de Ciurana J, Campa FJ (2009) Machine tool spindles. In: López de Lacalle LN, Lamikiz A (eds) Machine tools for high performance machining. Springer, London, pp 75-128

[2] Scandiffio I, Diniz AE, de Souza AF (2016) Evaluating surface roughness, tool life , and machining force when milling free-form shapes on hardened AISI D6 steel. Int J Adv Manuf Technol 82:2075-2086. https://doi.org/10.1007/s00170-015-7525-0

[3] de Oliveira AJ, Diniz AE (2009) Tool life and tool wear in the semi-finish milling of inclined surfaces. J Mater Process Technol 209:5448-5455.

https://doi.org/10.1016/j.jmatprotec.2009.04.022

[4] Kull Neto H, Diniz AE, Pederiva R (2016) Influence of tooth passing frequency, feed direction, and tool overhang on the surface roughness of curved surfaces of hardened steel. Int J Adv Manuf Technol 82:753-764. https://doi.org/10.1007/s00170-015-7419-1

[5] Quintana G, de Ciurana J (2011) Chatter in machining processes: A review. Int J Mach Tools Manuf 51:363-376. https://doi.org/10.1016/j.ijmachtools.2011.01.001

[6] Altintas Y (2012) Manufacturing Automation: Metal Cutting Mechanics, Machine Tool Vibrations, and CNC Design. Cambridge University Press, New York

[7] Yue C, Gao H, Liu X, Liang SY, Wang L (2019) A review of chatter vibration research in milling. Chinese J Aeronaut 32:215-242. https://doi.org/10.1016/j.cja.2018.11.007

[8] Waydande S, Mahajan DA, Gajjal SY (2014) A review on vibration attenuation of boring bar by using passive dampers. Int J Emerg Technol Adv Eng 4:117-122.

[9] Antonialli AI, Diniz AE, Pederiva R (2010) Vibration analysis of cutting force in titanium alloy milling. Int J Mach Tools Manuf 50:65-74. https://doi.org/10.1016/j.ijmachtools.2009.09.006

[10] Fei J, Lin B, Yan S, Ding M, Xiao J, Zhang J, Zhang X, Ji C, Sui T (2017) Chatter mitigation using moving damper. J Sound Vib 410:49-63 https://doi.org/10.1016/j.jsv.2017.08.033

[11] Yang Y, Dai W, Liu Q (2015) Design and implementation of two-degree-of-freedom tuned mass damper in milling vibration mitigation. J Sound Vib 335:78-88.

https://doi.org/10.1016/j.jsv.2014.09.032

[12] Madoliat R, Hayati S, Ghasemi Ghalebahman A (2011) Investigation of chatter suppression in slender endmill via a frictional damper. Sci Iran 18:1069-1077. https://doi.org/10.1016/j.scient.2011.08.008

[13] Munoa J, Beudaert X, Dombovari Z, Altintas Y, Budak E, Brecher C, Stepan G (2016) Chatter suppression techniques in metal cutting. CIRP Annals 65:785-808.

https://doi.org/10.1016/j.cirp.2016.06.004

[14] Coromant S (2017) Silent Tools. Sandvik, Sandviken

[15] Wong CX, Daniel MC, Rongong JA (2009) Energy dissipation prediction of particle dampers. J Sound Vib 319:91-118. https://doi.org/10.1016/j.jsv.2008.06.027 
[16] Djemal F, Chaari R, Gafsi W, Chaari F, Haddar M (2019) Passive vibration suppression using ball impact damper absorber. Appl Acoust 147:72-76.

https://doi.org/10.1016/j.apacoust.2017.09.011

[17] Paul PS, Raja P, Aruldhas P, Pringle S, Shaji E (2018) Effectiveness of particle and mass impact damping on tool vibration during hard turning process. Proc Inst Mech Eng Part B J Eng Manuf 232:776-786. https://doi.org/10.1177/0954405416660995

[18] Albuquerque MV (2016) Modelagem e análise dinâmica de um absorvedor de vibrações por efeito de impacto. Dissertation. University of Campinas

[19] Sims ND, Amarasinghe A, Ridgway K (2005) Particle dampers for workpiece chatter mitigation. Proceedings of the ASME 2005 International Mechanical Engineering Congress and Exposition 825-832. https://doi.org/10.1115/IMECE2005-82687

[20] Suyama DI, Diniz AE, Pederiva R (2016) The use of carbide and particle-damped bars to increase tool overhang in the internal turning of hardened steel. Int J Adv Manuf Technol 86:2083-2092. https://doi.org/10.1007/s00170-015-8328-z

[21] Diniz AE, da Silva WTA, Suyama DI, Pederiva R, Albuquerque MV (2019) Evaluating the use of a new type of impact damper for internal turning tool bar in deep holes. Int J Adv Manuf Technol 101:1375-1390. https://doi.org/10.1007/s00170-018-3039-х

[22] Galarza FAM, Albuquerque MV, Antonialli AIS, Pederiva R, Diniz AE (2020) Design and experimental evaluation of an impact damper to be used in a slender end mill tool in the machining of hardened steel. Int J Adv Manuf Technol 106:2553-2567. https://doi.org/10.1007/s00170-019-04786-9

[23] ISO (1996) Geometrical Product Specifications (GPS) - Surface texture: Profile method Nominal characteristics of contact (stylus) instruments, ISO 3274:1996.

[24] Kull Neto H, Diniz AE, Pederiva R (2016) The influence of cutting forces on surface roughness in the milling of curved hardened steel surfaces. Int J Adv Manuf Technol 84:1209-1218. https://doi.org/10.1007/s00170-015-7811-X

[25] Saciotto VR, Diniz AE, Albuquerque MV, Pederiva R (2019) Simulação do amortecimento de ferramenta de usinagem usando cilindro de aço, esferas de aço e de tungstênio. Anais do XXIII Colóquio de Usinagem 74-78.

[26] Kull Neto H, Diniz AE, Pederiva R (2016) Tool life and surface roughness in the milling of curved hardened-steel surfaces. Int J Adv Manuf Technol 87:2983-2995

https://doi.org/10.1007/s00170-016-8640-2 
Figures

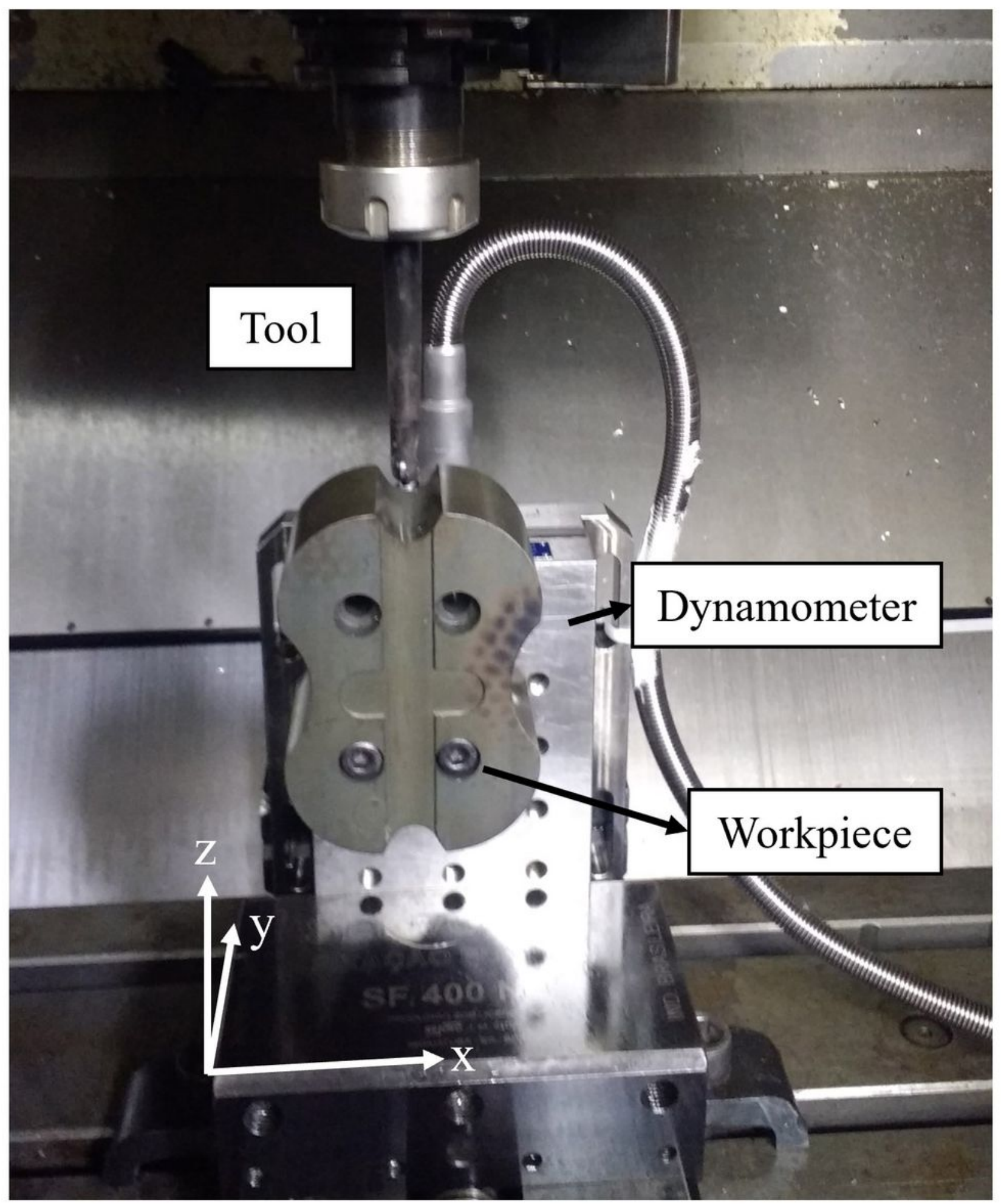

Figure 1

Workpiece and dynamometer fixation. 

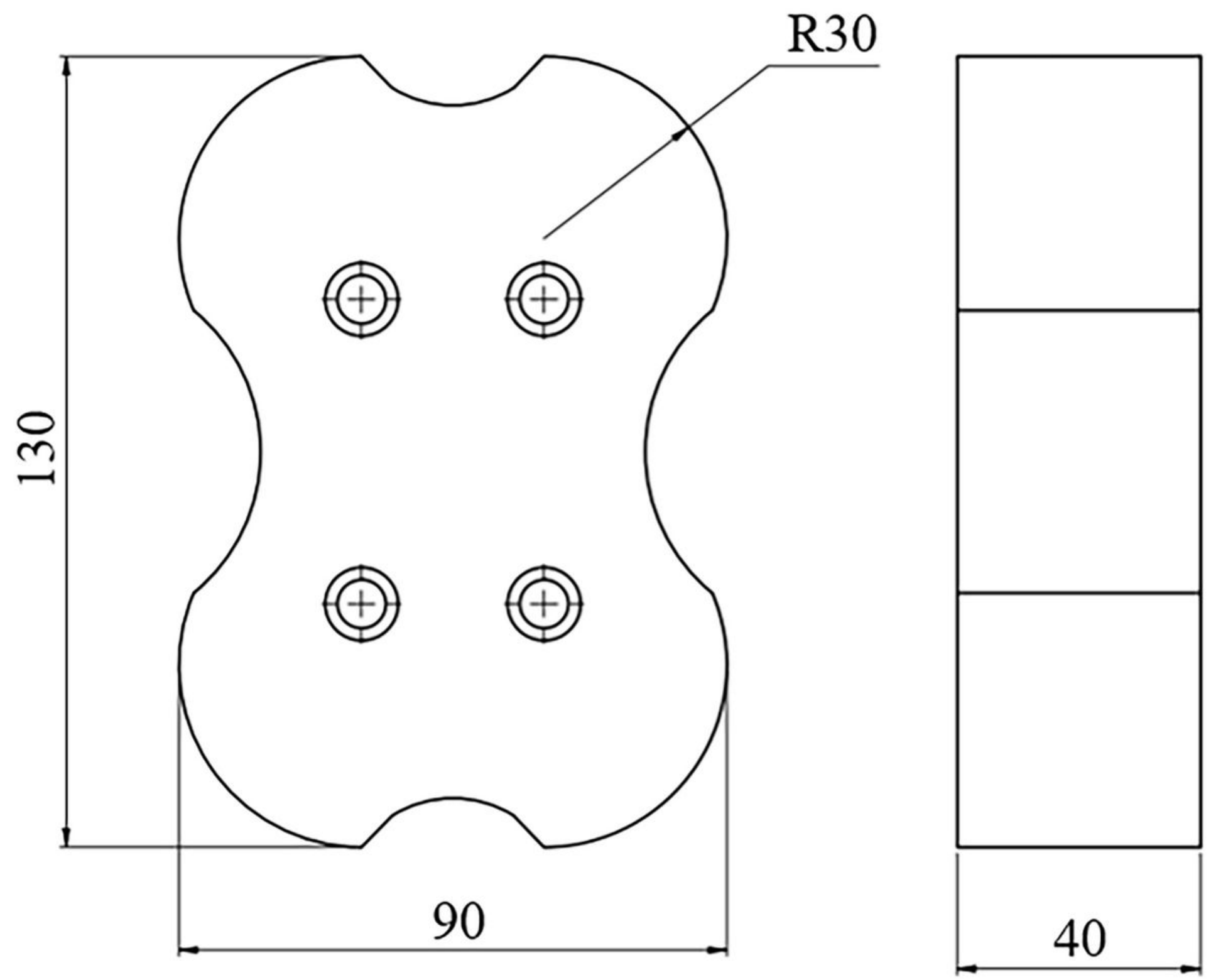

Figure 2

Schematic drawing of the workpiece. 
145

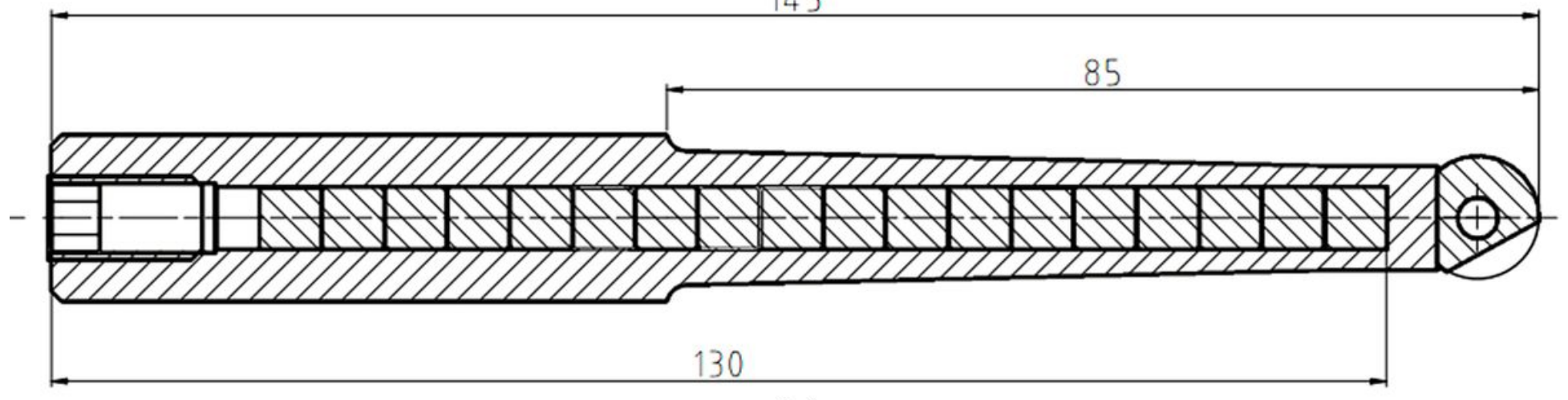

(a)

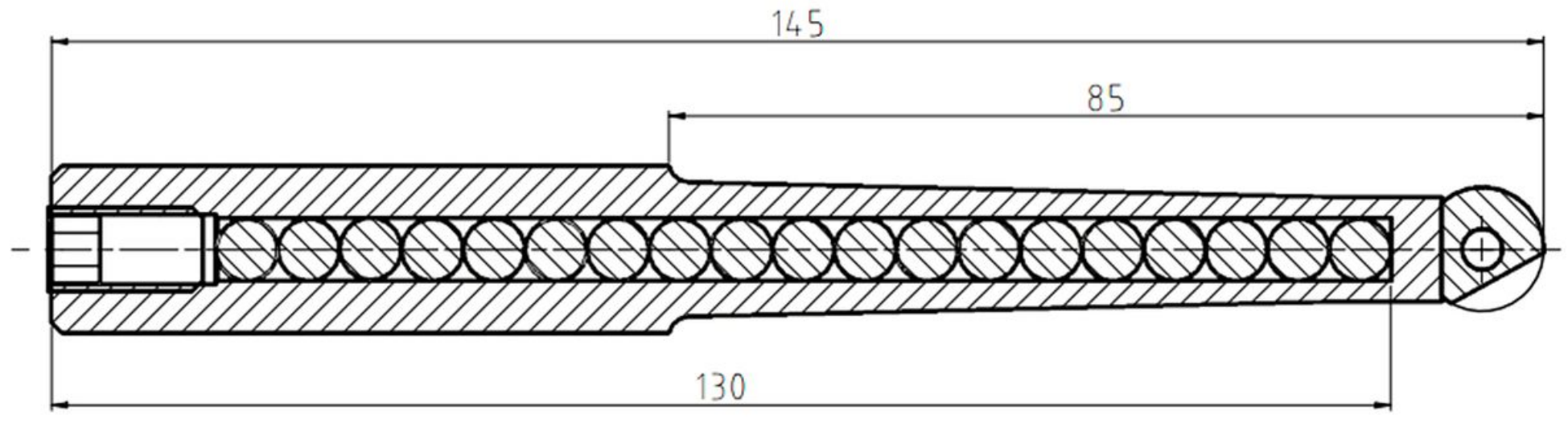

(b)

Figure 3

Schematic drawing of the tool holder with cylinders (a) and spheres (b). 


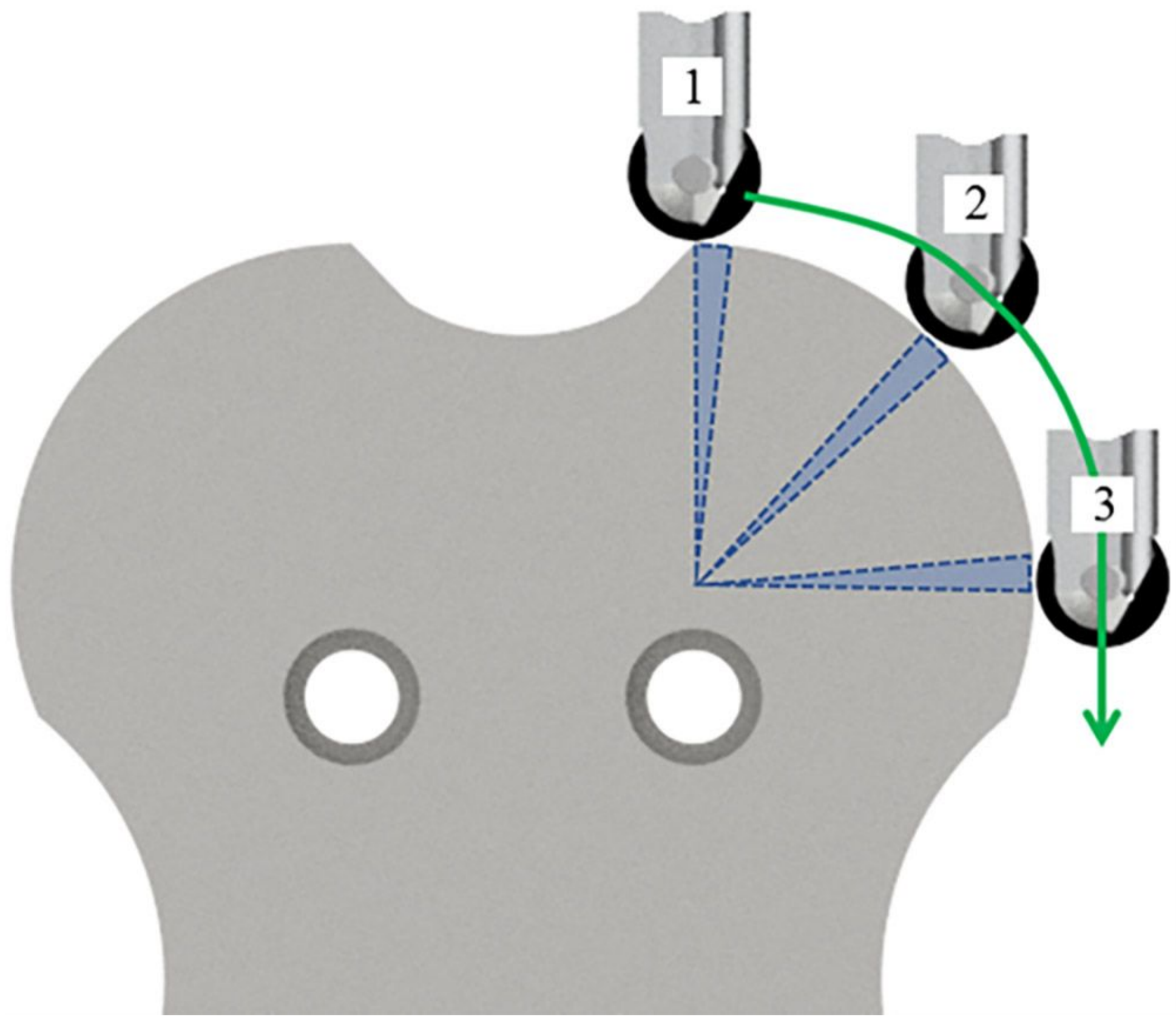

Figure 4

Tool feed path during machining. 


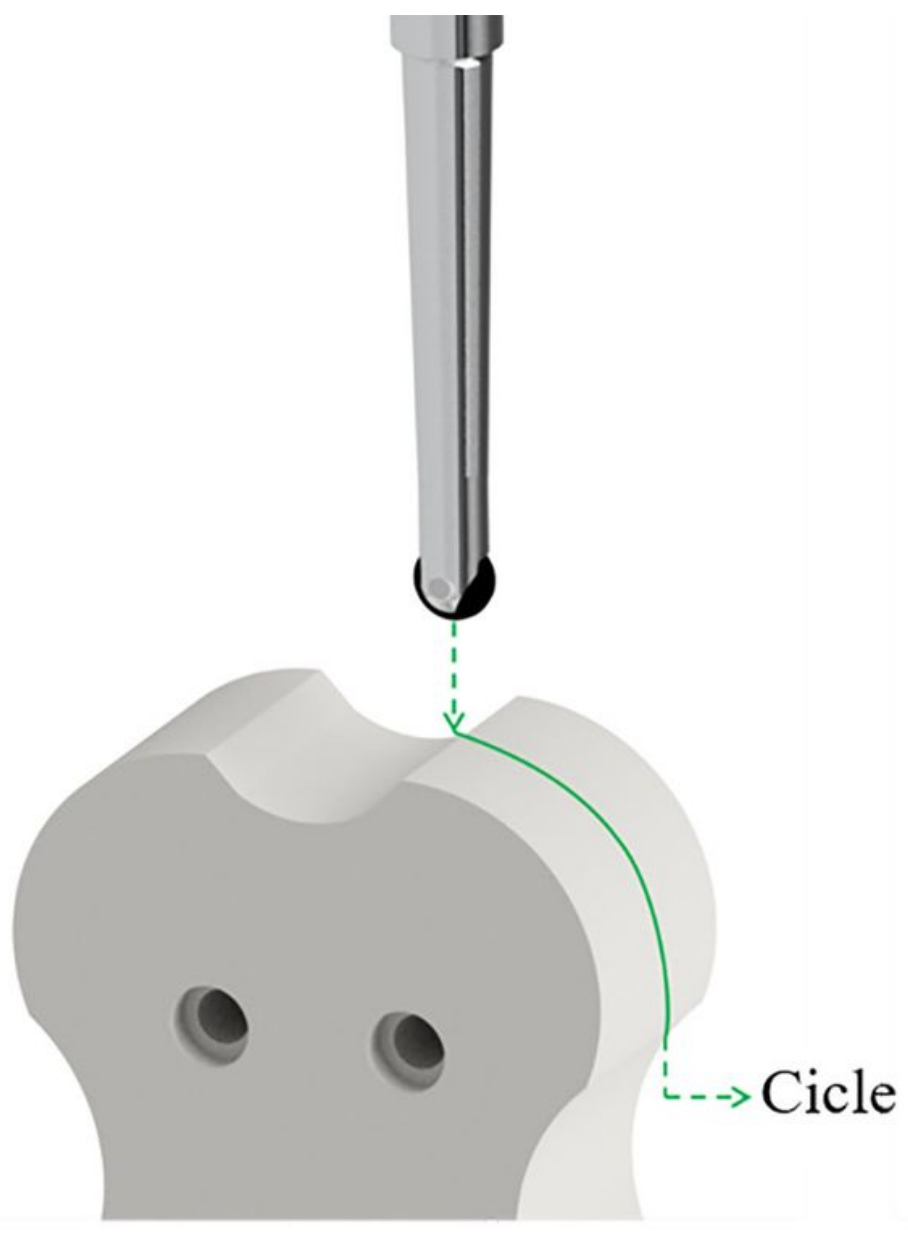

a

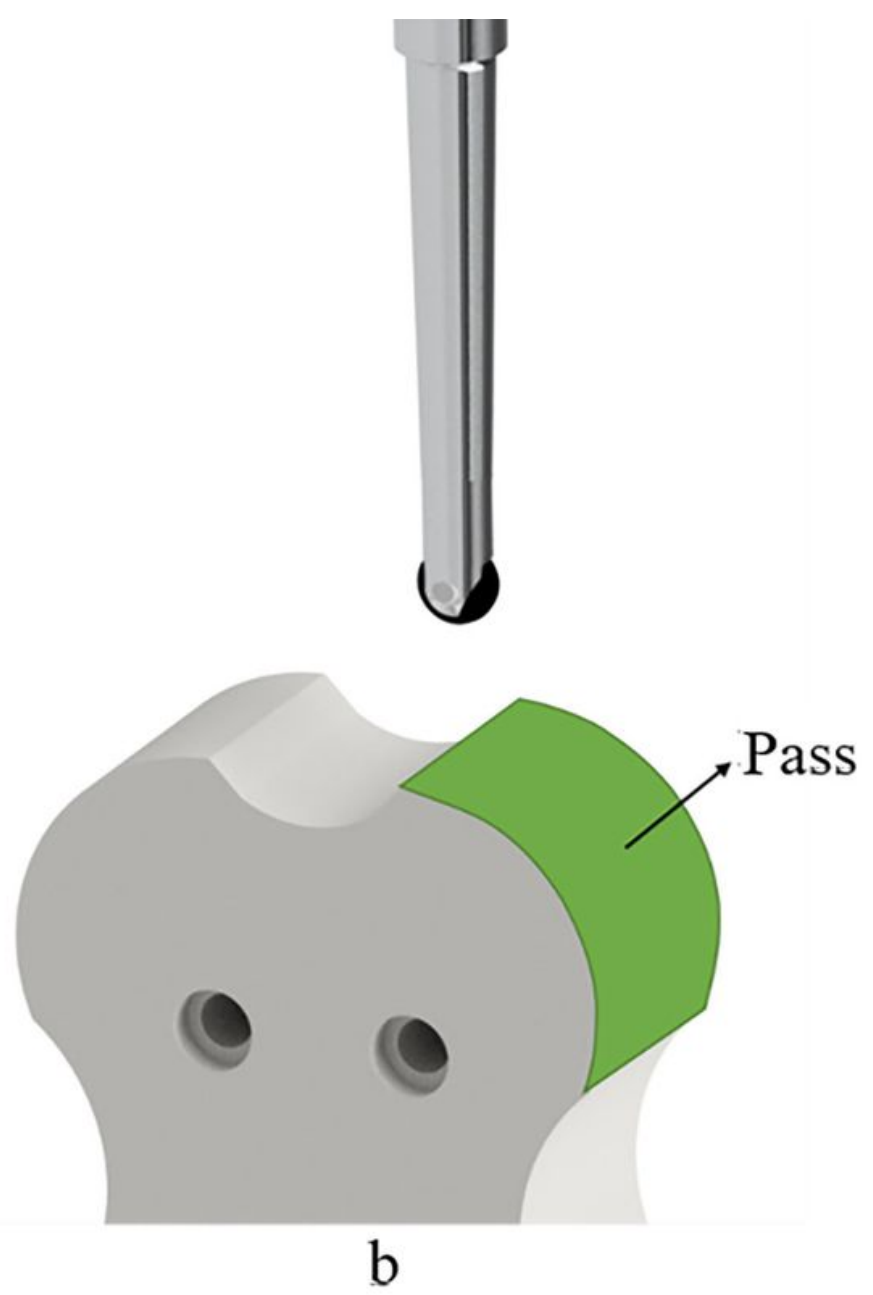

Figure 5

Representation of one cycle and one pass. 


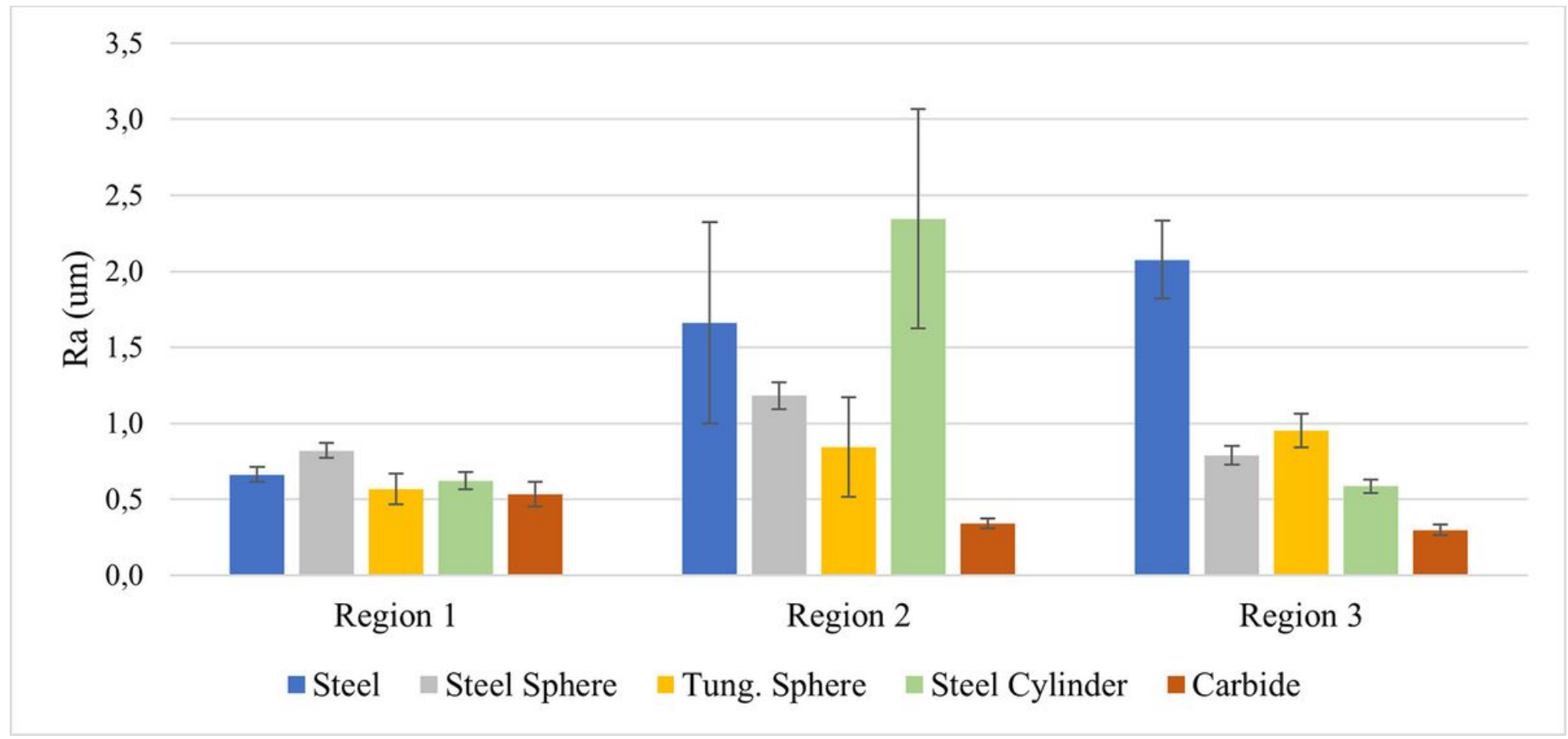

Figure 6

Roughness generated at the end of tool life $(V B m a x=0.2 \mathrm{~mm})$ in the 3 regions studied.

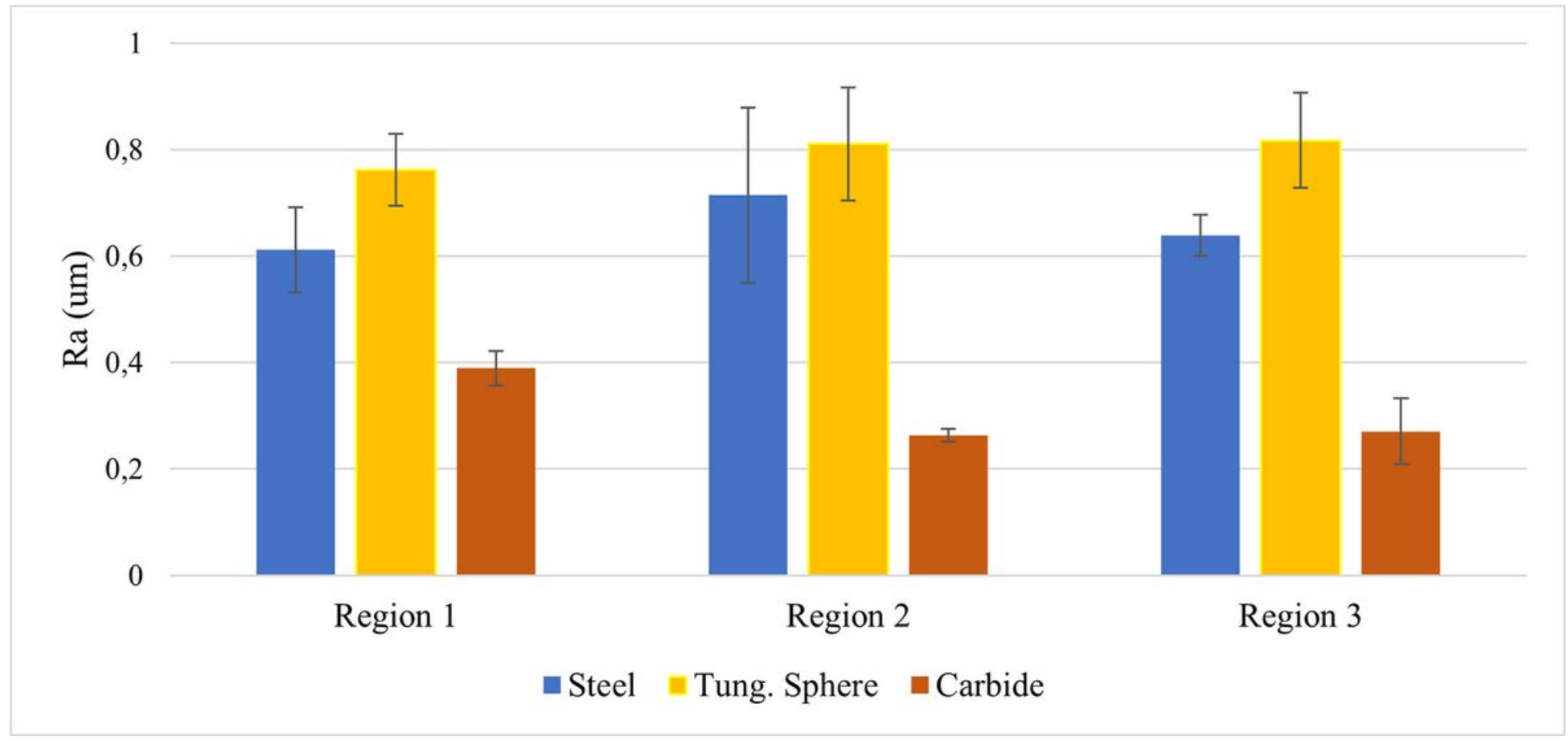

Figure 7

Roughness generated during the first pass of the tool in the 3 regions studied. 


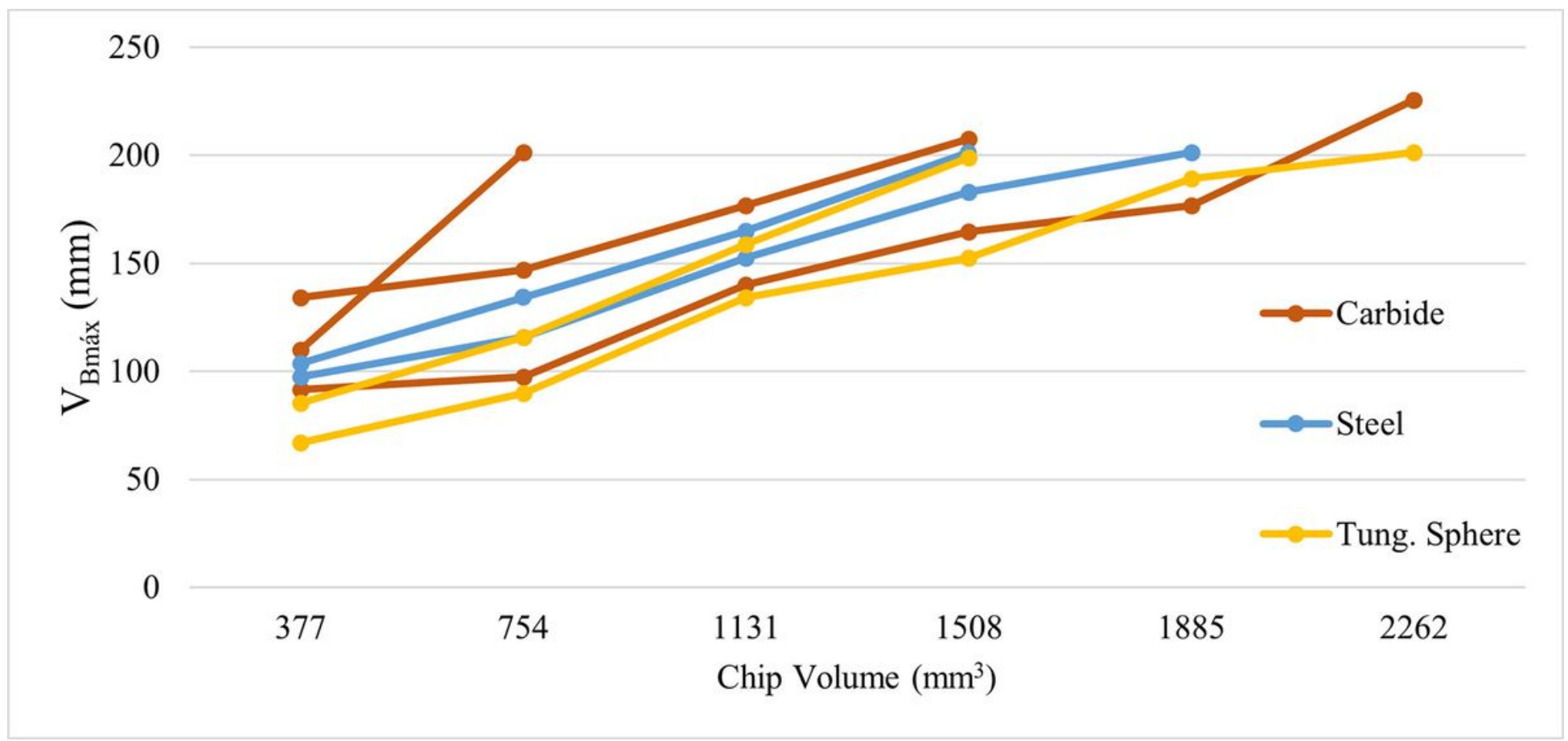

Figure 8

Tool flank wear by chip volume produced in $\mathrm{mm} 3$

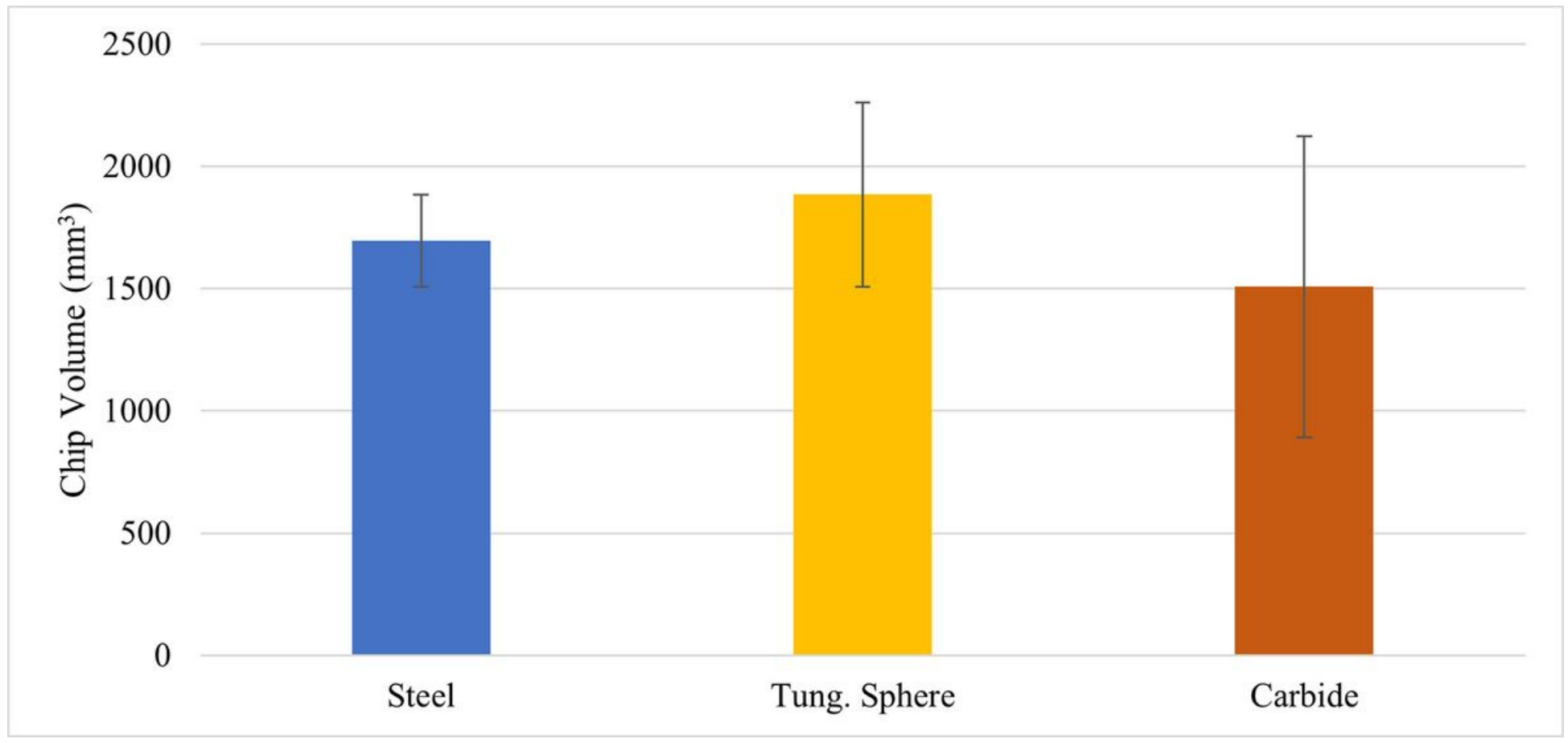

Figure 9

Tool life by chip volume produced in $\mathrm{mm} 3$ 

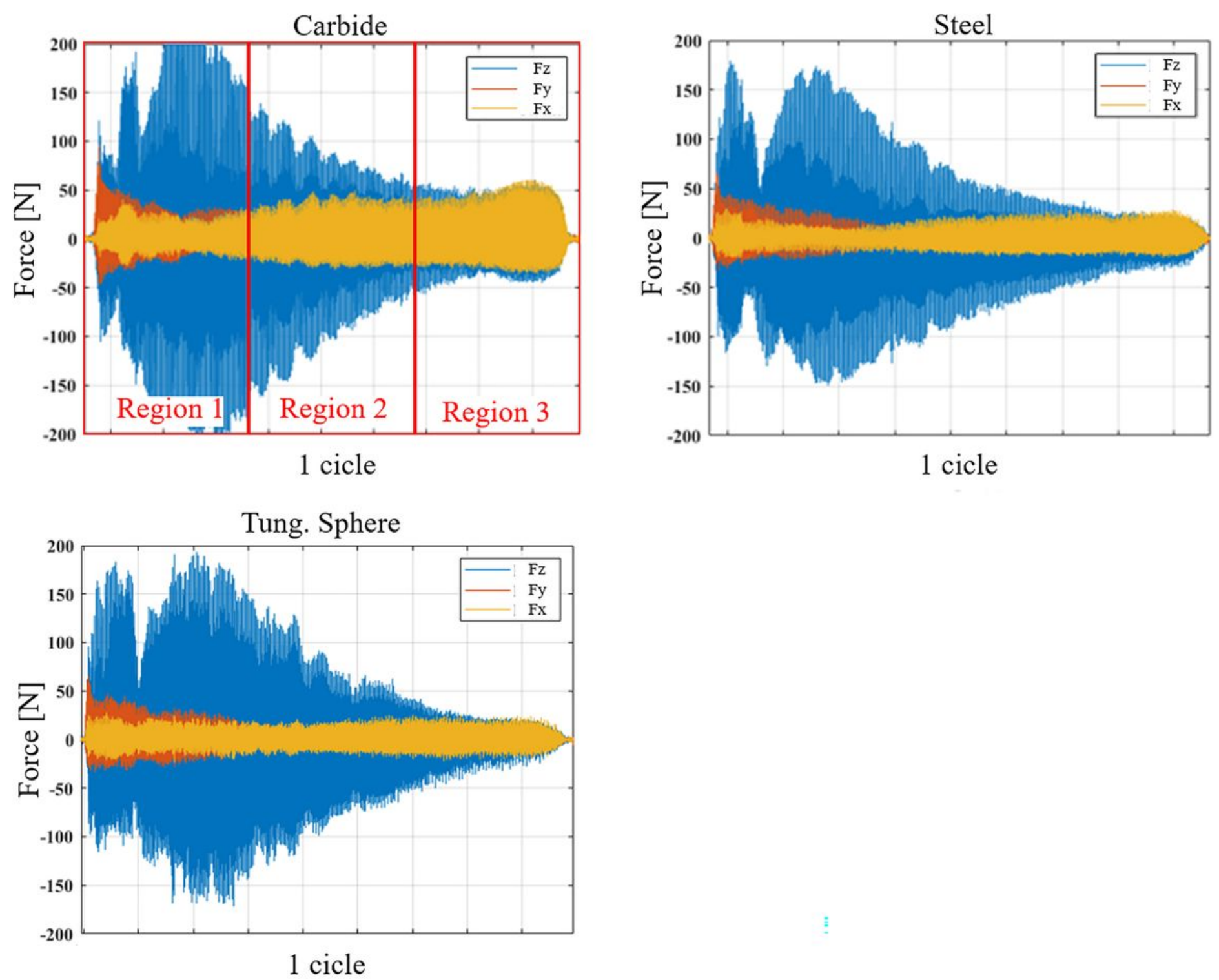

Figure 10

Force signals in $\mathrm{X}, \mathrm{Y}$ and $\mathrm{Z}$ directions during the first pass of the tool. 

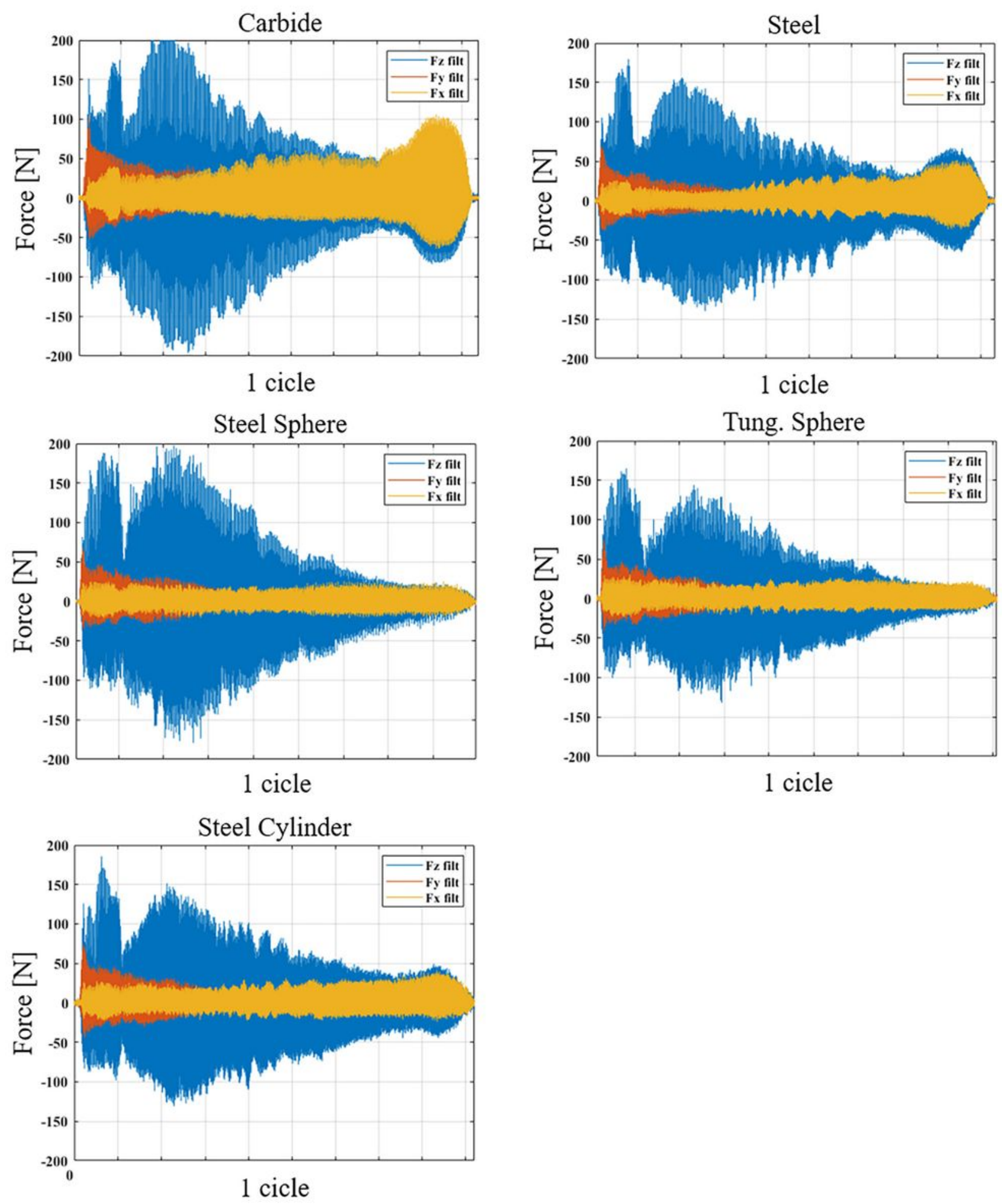

Figure 11

Force signals in $\mathrm{X}, \mathrm{Y}$ and $\mathrm{Z}$ directions during the first pass of the tool at the end of tool life. 

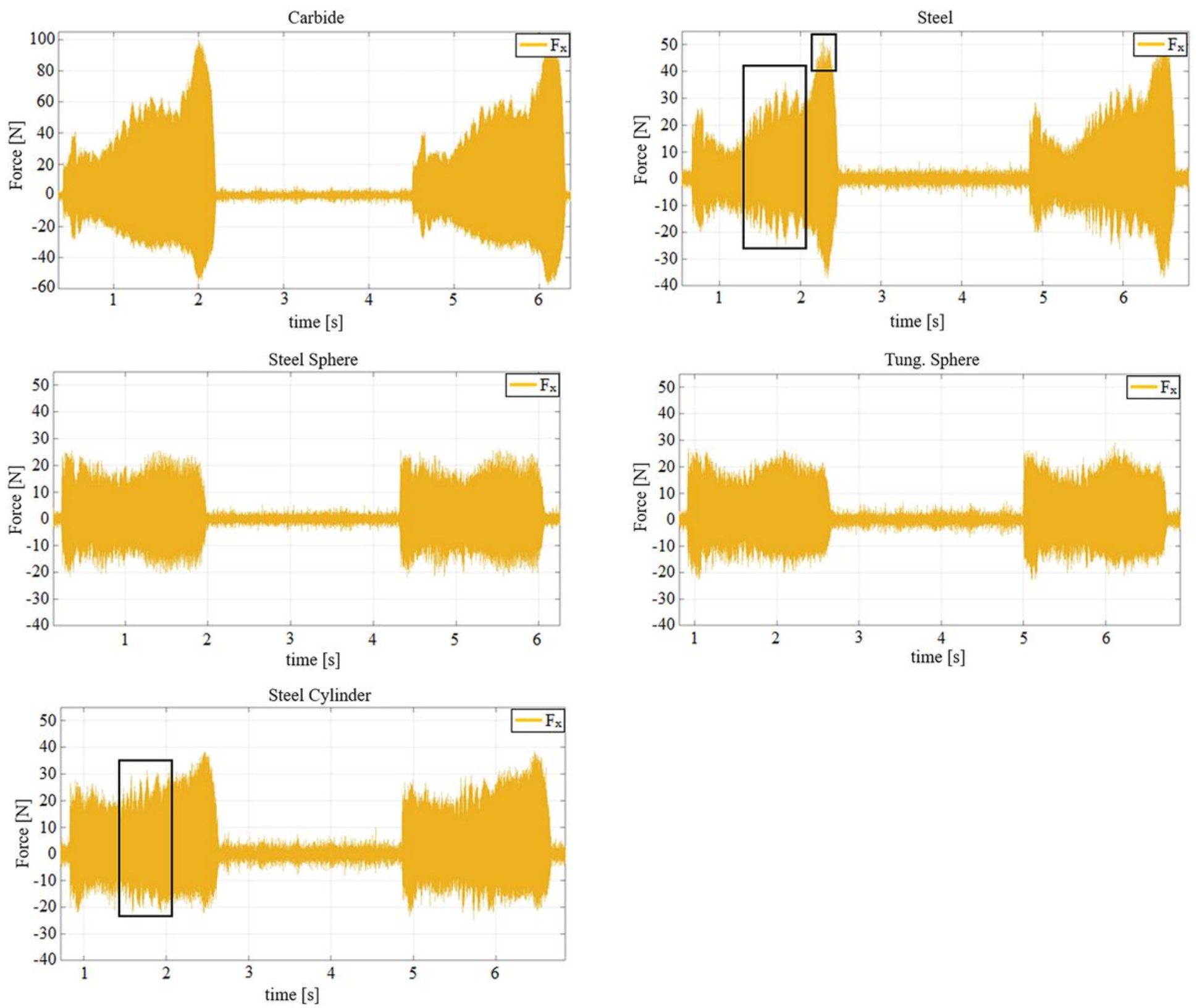

Figure 12

Force signal in X direction for two tool cycles. 

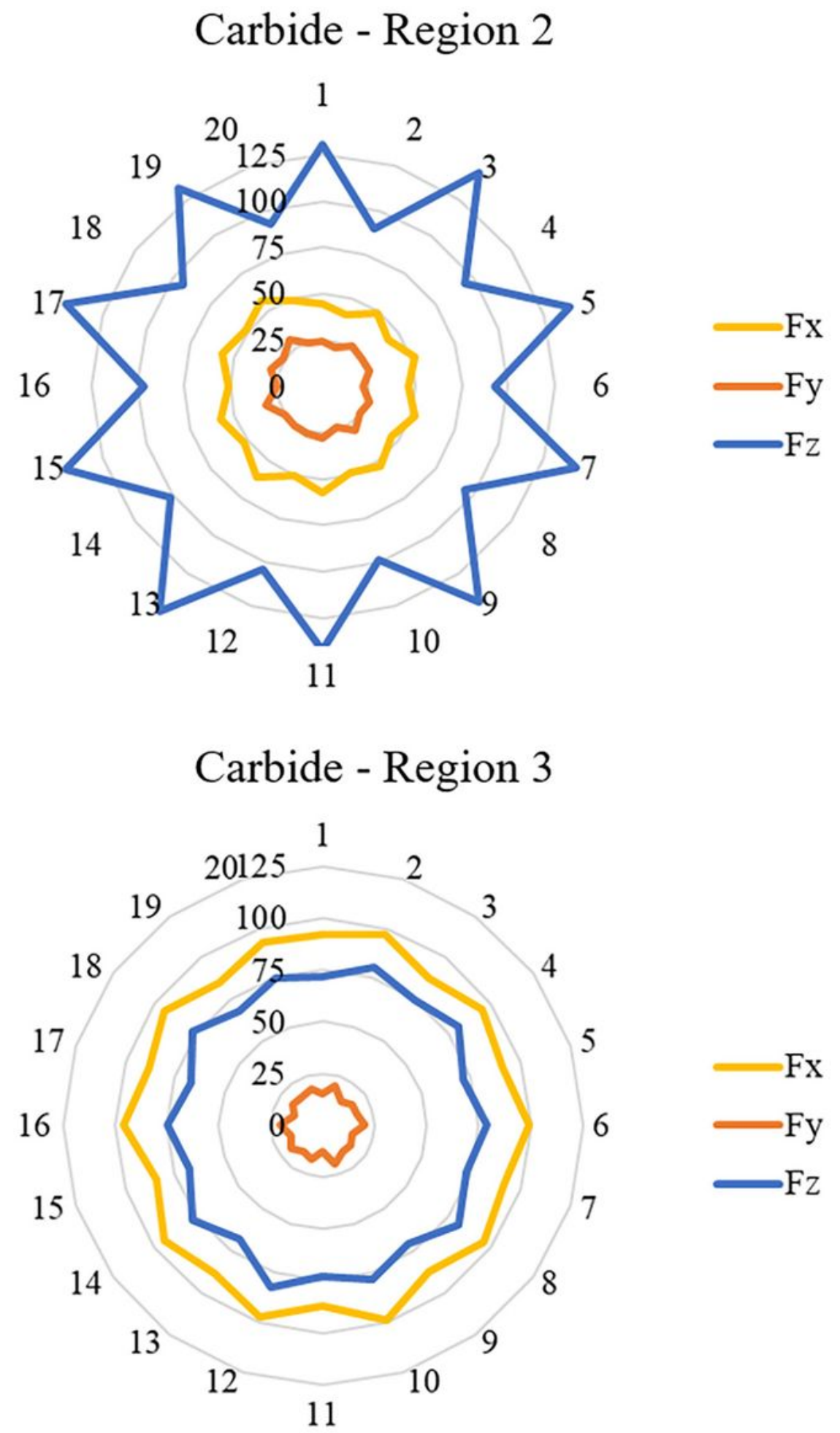

Figure 13

Peaks of force signal for the carbide tool holder. 


\section{Carbide - Region 2}
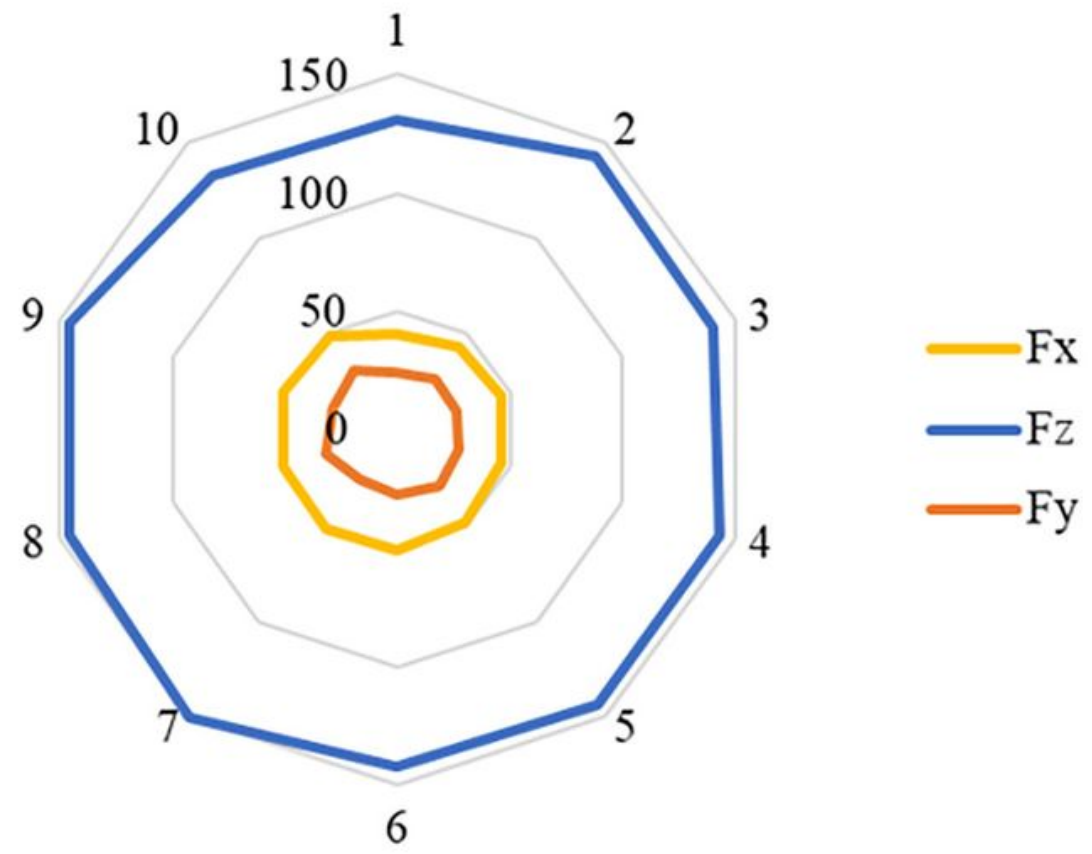

Carbide - Region 3

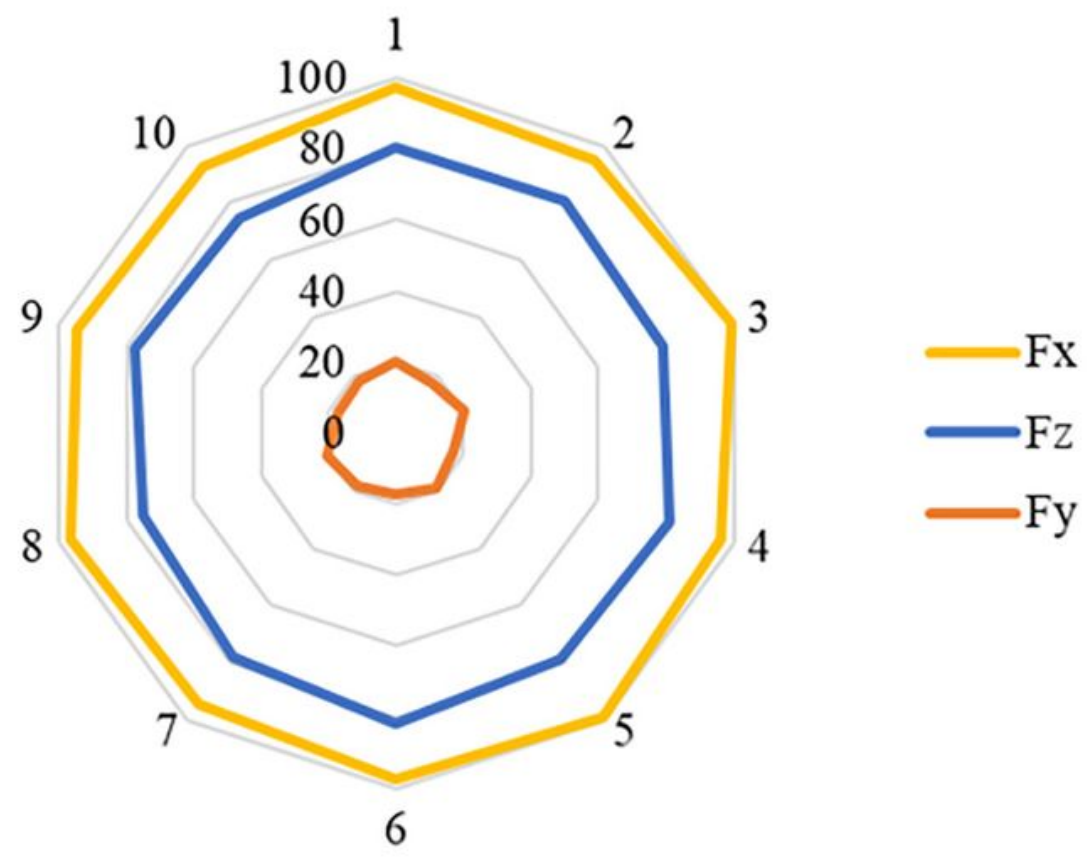

Figure 14

Peaks of force signal in one edge for the carbide tool holder. 
Carbide - Region 2

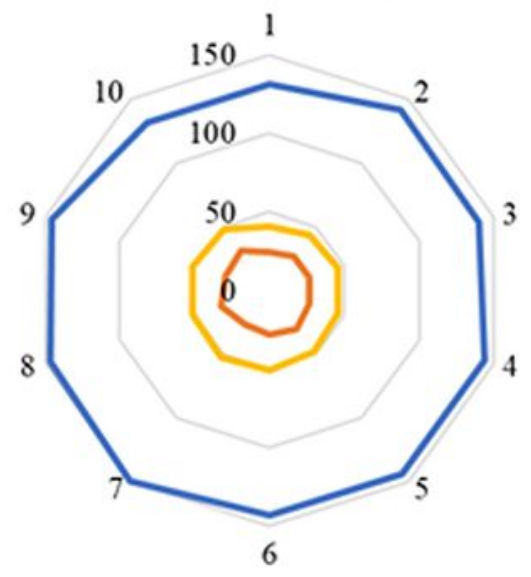

$-\mathrm{Fx}$
$-\mathrm{Fz}$
$-\mathrm{Fy}$

Steel Cylinder - Region 2
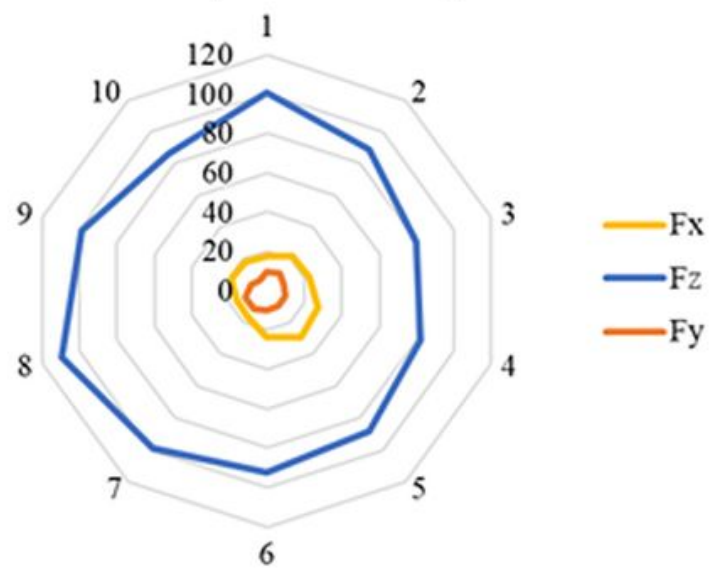

Tung. Sphere - Region 2

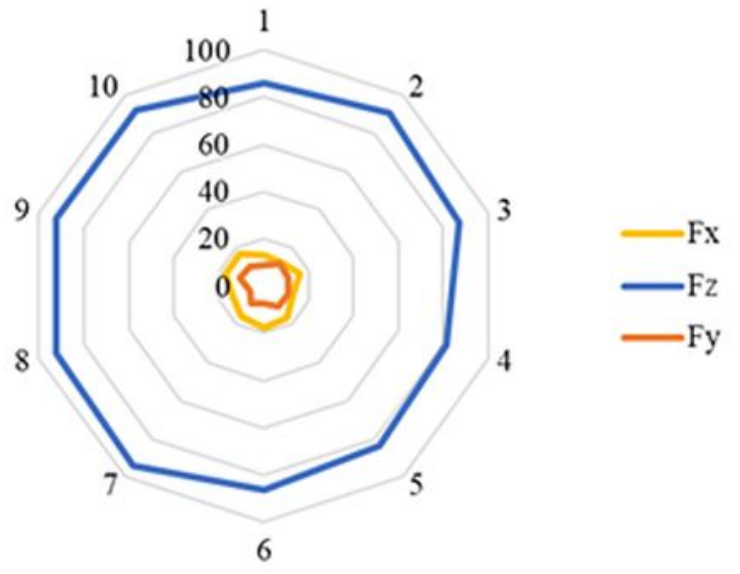

Steel - Region 2

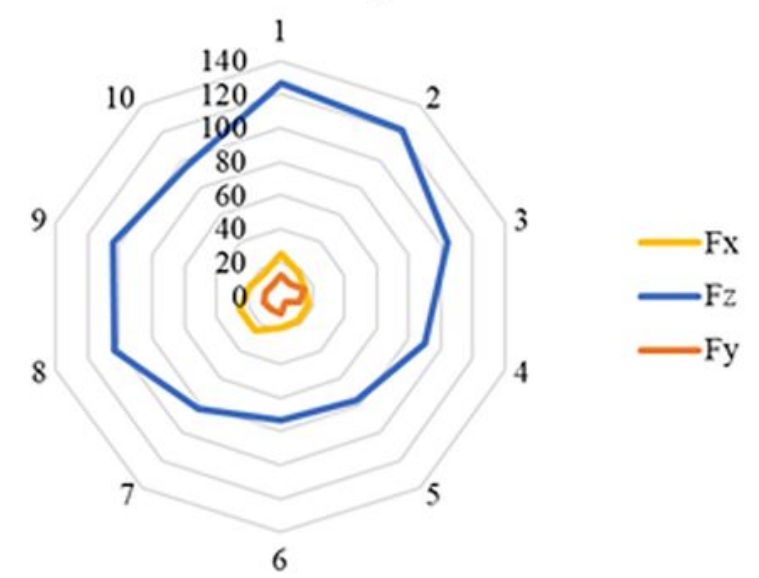

Steel Sphere - Region 2

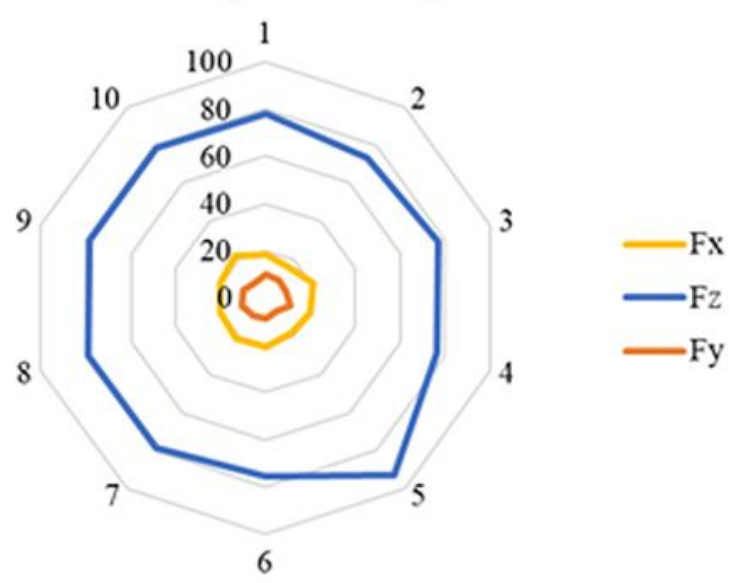

\section{Figure 15}

Peaks of force signal in one edge - Region 2 


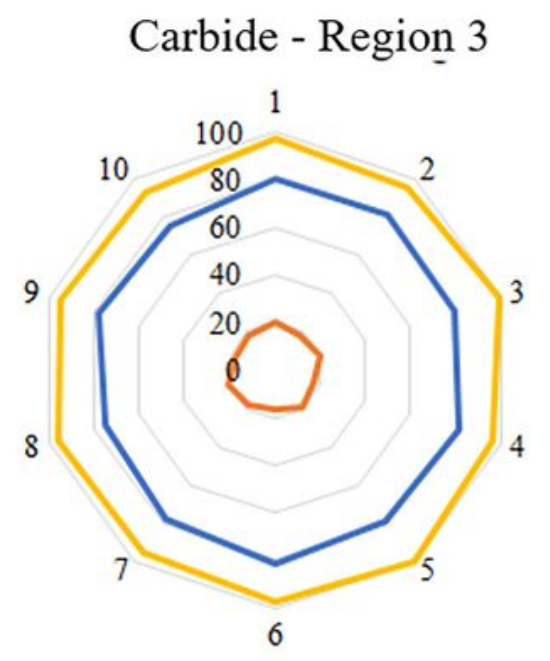

Steel Cylinder - Region 3

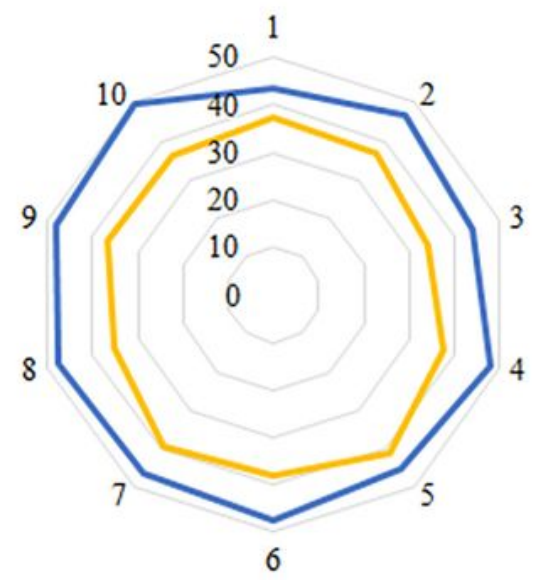

Tung. Sphere - Region 3

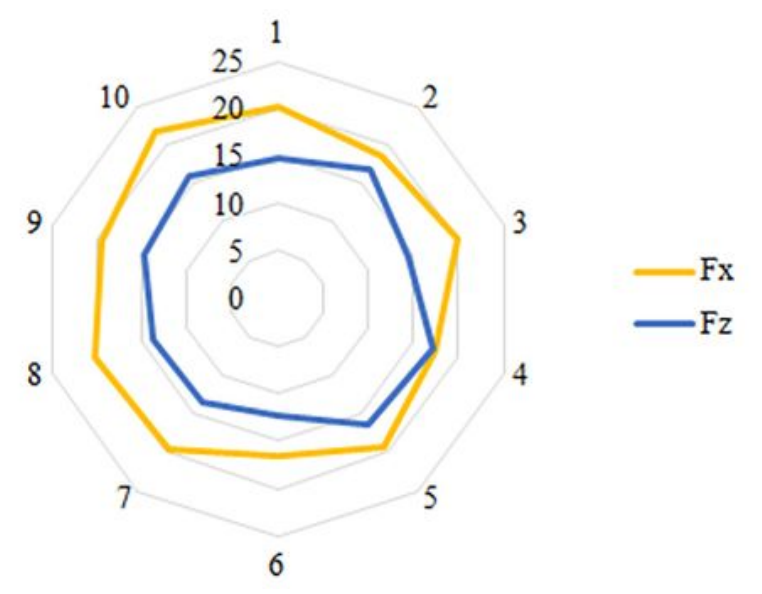

\section{Figure 16}

Peaks of force signal in one edge - Region 3 


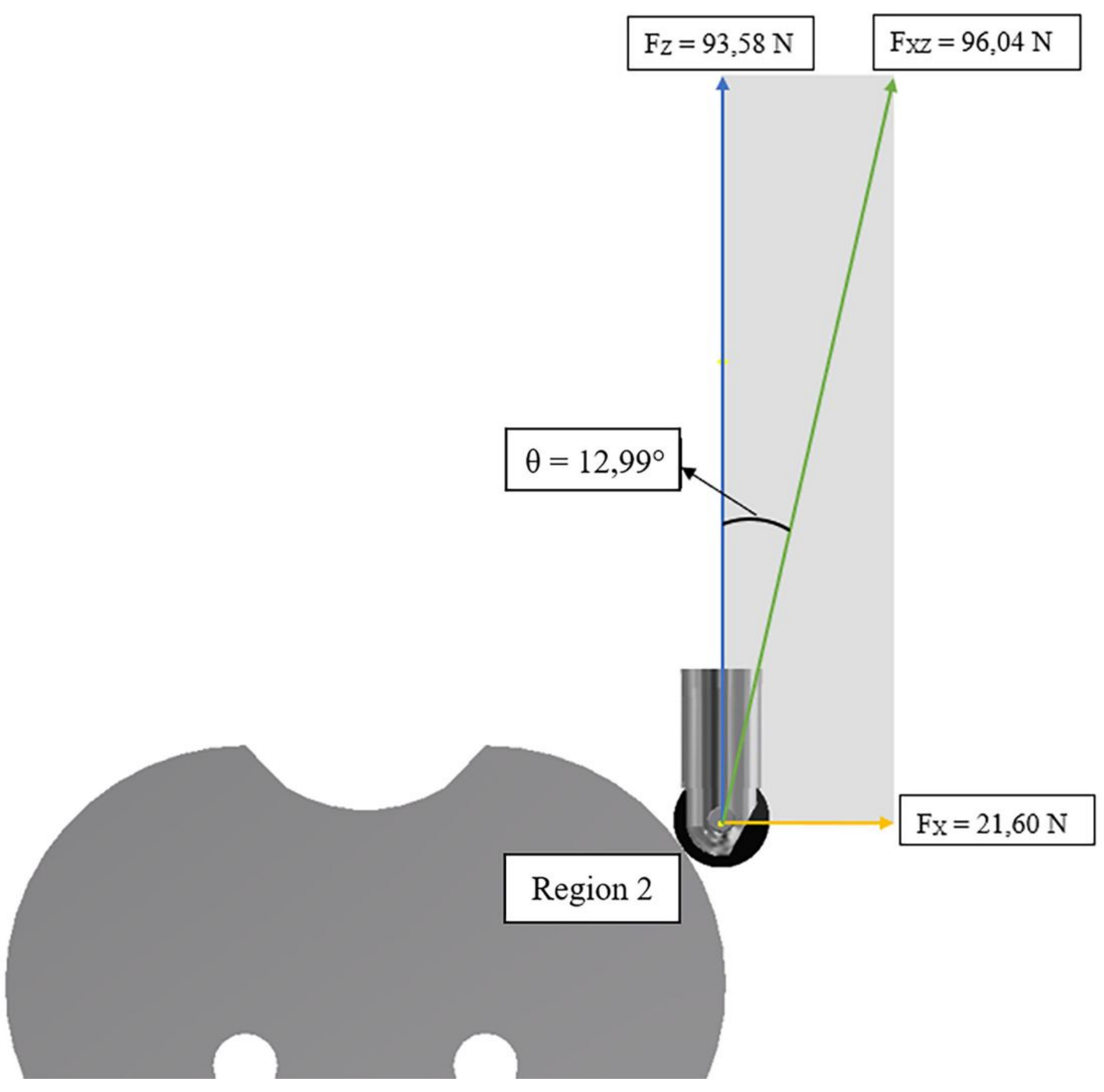

Figure 17

Representation of $\mathrm{X}$ and $\mathrm{Z}$ forces and resulting in region 2: tool with cylinders 


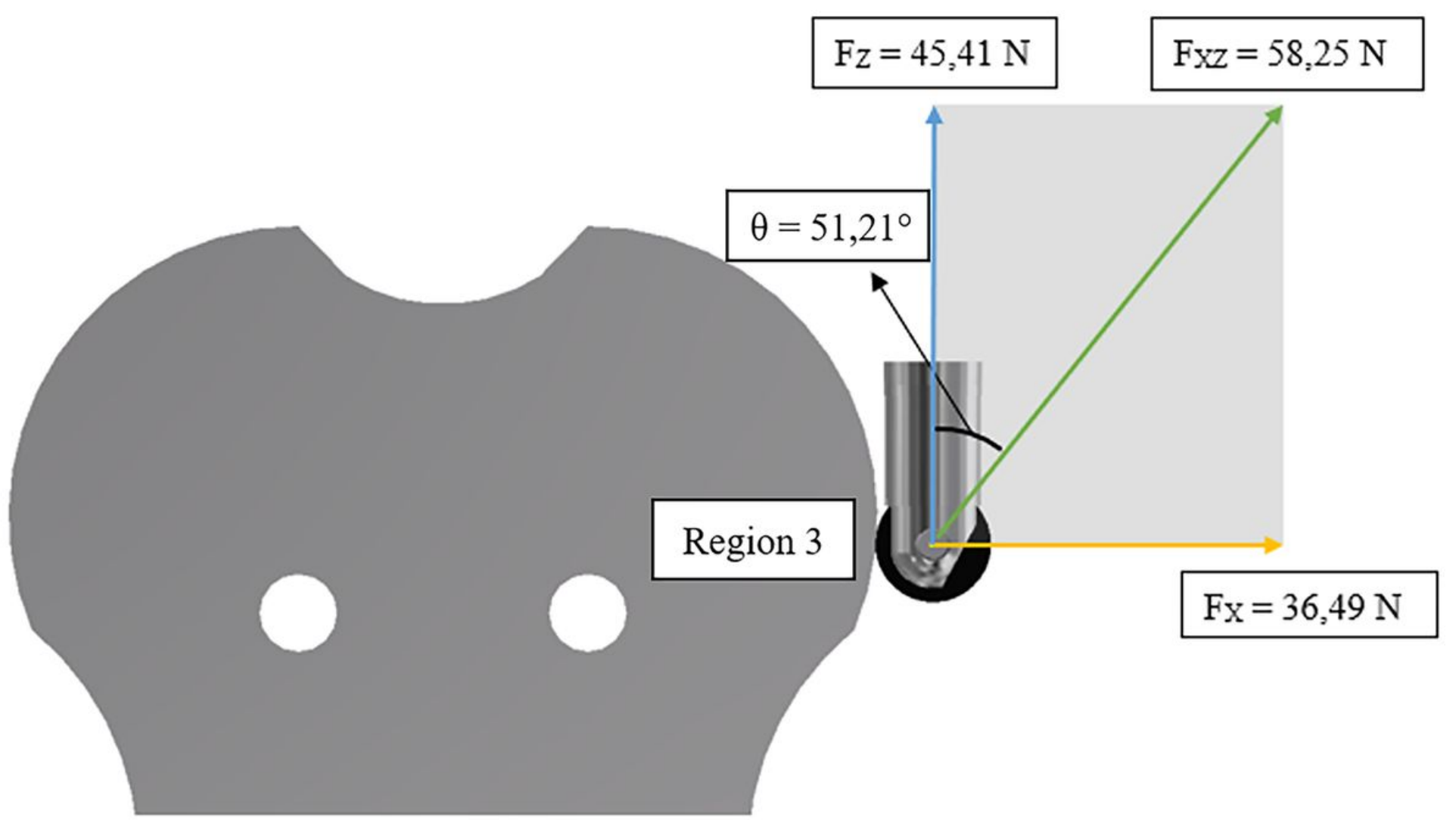

Figure 18

Representation of $\mathrm{X}$ and $\mathrm{Z}$ forces and resulting in region 3: tool with cylinders 